\title{
The detectability of nitrous oxide mitigation efficacy in intensively grazed pastures using a multiple-plot micrometeorological technique
}

\author{
A. M. S. McMillan ${ }^{1, *}$, M. J. Harvey ${ }^{1}$, R. J. Martin ${ }^{1}$, A. M. Bromley ${ }^{1}$, M. J. Evans ${ }^{1}$, S. Mukherjee ${ }^{2}$, and J. Laubach ${ }^{3}$ \\ ${ }^{1}$ National Institute of Water and Atmospheric Research, Private Bag 14901, Wellington, 6241, New Zealand \\ ${ }^{2}$ Department of Geography, University of Canterbury, Private Bag 4800, Christchurch, 8020, New Zealand \\ ${ }^{3}$ Landcare Research, P.O. Box 40, Lincoln, 7640, New Zealand \\ *now at: Landcare Research, Private Bag 11052, Palmerston North, 7640, New Zealand
}

Correspondence to: A. M. S. McMillan (mcmillana@landcareresearch.co.nz)

Received: 29 August 2013 - Published in Atmos. Meas. Tech. Discuss.: 16 October 2013

Revised: 8 January 2014 - Accepted: 21 March 2014 - Published: 7 May 2014

\begin{abstract}
Methodologies are required to verify agricultural greenhouse gas mitigation at scales relevant to farm management. Micrometeorological techniques provide a viable approach for comparing fluxes between fields receiving mitigation treatments and control fields. However, they have rarely been applied to spatially verifying treatments aimed at mitigating nitrous oxide emission from intensively grazed pastoral systems. We deployed a micrometeorological system to compare $\mathrm{N}_{2} \mathrm{O}$ flux among several $\sim 1.5$ ha plots in intensively grazed dairy pasture. The sample collection and measurement system is referred to as the Field-Scale Nitrous Oxide Mitigation Assessment System (FS-NOMAS) and used a tuneable diode laser absorption spectrometer to measure $\mathrm{N}_{2} \mathrm{O}$ gradients to high precision at four locations along a $300 \mathrm{~m}$ transect. The utility of the FS-NOMAS to assess mitigation efficacy depends largely on its ability to resolve very small vertical $\mathrm{N}_{2} \mathrm{O}$ gradients. The performance of the FSNOMAS was assessed in this respect in laboratory and fieldbased studies. The FS-NOMAS could reliably resolve gradients of $0.039 \mathrm{ppb}$ between a height of 0.5 and $1.0 \mathrm{~m}$. The gradient resolution achieved corresponded to the ability to detect an inter-plot $\mathrm{N}_{2} \mathrm{O}$ flux difference of $26 \mu \mathrm{g} \mathrm{N} \mathrm{N}_{2} \mathrm{O}-\mathrm{N} \mathrm{m}^{-2} \mathrm{~h}^{-1}$ under the most commonly encountered conditions of atmospheric mixing (quantified here by a turbulent transfer coefficient), but this ranged from 11 to $59 \mu \mathrm{g} \mathrm{N} \mathrm{N}_{2} \mathrm{O}-\mathrm{N} \mathrm{m}^{-2} \mathrm{~h}^{-1}$ as the transfer coefficient ranged between its 5 th and 95 th percentile. Assuming a likely value of $100 \mu \mathrm{g} \mathrm{N} \mathrm{N}_{2} \mathrm{O}-\mathrm{N} \mathrm{m}^{-2} \mathrm{~h}^{-1}$ for post-grazing $\mathrm{N}_{2} \mathrm{O}$ fluxes from intensively grazed New Zealand dairy pasture, the system described here would be capable of detecting a mitigation efficacy of $26 \%$ for a single
\end{abstract}

(40 min) comparison. We demonstrate that the system has considerably greater sensitivity to treatment effects by measuring cumulative fluxes over extended periods.

\section{Introduction}

Agricultural soils are responsible for a substantial portion of the total global emissions of $\mathrm{N}_{2} \mathrm{O}$. While the uncertainty in the total source strength of agricultural emissions is large ( $>39 \%$ ) the estimate of the source strength during the $1990 \mathrm{~s}$ of agricultural soils was $2.8 \mathrm{Tg} \mathrm{N} \mathrm{yr}^{-1}$, which accounts for almost $42 \%$ of the global emissions during this period (IPCC, 2007). In New Zealand, outdoor livestock grazing is the predominant land use type and direct $\mathrm{N}_{2} \mathrm{O}$ emissions from soil following fertiliser and excretal nitrogen deposition on pasture account for more than $75 \%$ of New Zealand's reported anthropogenic $\mathrm{N}_{2} \mathrm{O}$ emissions (Ministry for the Environment, 2013). A nationally coordinated effort has been directed at the quantification of these fluxes for a range of characteristic pasture types and locations.

More recently, measurement campaigns have focused on assessing the efficacy of potential mitigation strategies, such as the application of a nitrification inhibitor, to reduce $\mathrm{N}_{2} \mathrm{O}$ emissions from grazed pasture. Such campaigns necessarily involve comparative experimental designs (i.e. mitigation treatment versus control). The majority of such assessments have been implemented at the experimental plot scale $\left(<1 \mathrm{~m}^{2}\right)$ using static flux chambers (e.g. Gillingham et al., 2012). Typically, flux measurements are taken from plots that 
have been treated with known inputs of nitrogen, in the form of artificial urine and/or urea fertiliser, and with or without the addition of the mitigant of interest.

These experiments are valuable for developing emissions factors for mitigation for incorporation into greenhouse gas inventories (Clough et al., 2007), but to extrapolate these measured emissions to an operational field scale, several assumptions are required. These include (1) that the experimental conditions imposed in the plot (soil moisture, nitrogen and application of mitigant) can be reliably extrapolated to the field including the inhomogeneity of deposited nitrogen at field scale; (2) that there is a known relationship between the efficiency of the mitigant at the field scale as compared to the experimental plot scale; (3) that the artefacts of chamber sampling are minor compared to the magnitude of the differences between the fluxes.

It is therefore desirable to obtain a field scale estimate of mitigation efficacy by comparing $\mathrm{N}_{2} \mathrm{O}$ emissions between treated and untreated fields using an independent measurement technique. It is generally impractical to attempt representative sampling of $\mathrm{N}_{2} \mathrm{O}$ fluxes by random placement of chambers within a paddock due to the uneven nature of excreta-N deposition (Giltrap et al., 2012), which is the main driver of $\mathrm{N}_{2} \mathrm{O}$ emissions in grazed pasture.

Micrometeorological techniques provide a means for verifying a mitigation efficacy at the field scale. They address concerns about chamber methodology by: (1) avoiding interference with the soil/atmosphere environment by measuring $\mathrm{N}_{2} \mathrm{O}$ in air moving over the surface of interest; (2) measuring at a spatial scale that integrates the spatial heterogeneity that is a result of livestock excreta-N deposition; (3) measuring quasi-continuously and automatically, yielding several flux estimates per treatment per day at regular intervals; (4) measuring at the scale similar to that of the basic unit of commercial management (e.g. the 1 to 10 ha field). While a micrometeorological approach may address some issues associated with static flux chamber sampling, there are relatively few studies in which micrometeorological systems have been deployed in a comparative mode to measure field treatment effects of $\mathrm{N}_{2} \mathrm{O}$ emissions (Wagner-Riddle et al., 1996, 2007) and they have not previously been applied to the intensively grazed pastoral system.

Agricultural fluxes of $\mathrm{N}_{2} \mathrm{O}$ impart very small changes to the background $\mathrm{N}_{2} \mathrm{O}$ mixing ratio. When attempting to measure these fluxes using a micrometeorological approach, we are not enclosing the surface of interest and $\mathrm{N}_{2} \mathrm{O}$ fluxes from the surface of interest are diluted by the background air. Therefore, an extremely sensitive analyser with a high level of analytical precision is required. Laser-based optical systems have been most commonly deployed to address this issue but they are expensive and it is potentially cost prohibitive to have multiple sensors deployed during one experiment.

A cost-effective solution is to design a sample collection system capable of delivering air samples from multiple plots to a single analyser. Making comparisons among different treatments requires an additional level of precision as the task will demand detecting differences between fluxes from mitigated and control plots. Such a design would require consideration of the layout of the experimental plots relative to the measurement points. Since the source area is not constrained (as it would be using a static flux chamber) we must ensure that the sampled area is sufficiently large in order to minimise cross-contamination by fluxes from areas outside of the plot of interest. This requires evaluation of the flux footprint (the extent of the area that contributes to the measured fluxes). In practical terms, the upper limit to the spatial separation between sampling points was limited by the distance over which we could reliably transport air in a tube from the sampling location to the analyser.

Here we describe a micrometeorological method, adapted from Pattey et al. (2006) and Wagner-Riddle et al. (1996), but applied to the specific problem of measuring mitigation efficacy in an intensively grazed pasture. We refer to our method as the Field-Scale Nitrous Oxide Mitigation Assessment System (or FS-NOMAS), describe a novel approach for calibrating our gradient measurement, and evaluate its performance in assessing mitigation efficacy from multiple-plot measurement on intensively grazed pasture. The specific mitigation strategy examined was the post-grazing application of the nitrification inhibitor, dicyandiamide (DCD), which has been found to reduce $\mathrm{N}_{2} \mathrm{O}$ emissions in a growing body of studies in New Zealand grazed systems (see Clough et al., 2007). This paper first assesses the ability of the FS-NOMAS to resolve small $\mathrm{N}_{2} \mathrm{O}$ gradients and then considers the applicability of the technique for assessing field-scale mitigation efficacy (i.e. the ability to resolve inter-plot flux differences).

\section{Methods and materials}

\subsection{Flux-gradient technique}

The flux gradient approach was selected as the best-suited method for multi-site sampling with a single analyser. The flux gradient technique has long been established for the measurement of trace gas fluxes from agricultural surfaces, with early studies investigating $\mathrm{CO}_{2}$ fluxes from wheat (Huber, 1952) and sugar beet (Monteith and Sceicz, 1960), and ammonia fluxes from grazed pasture (Denmead et al., 1974).

A tunable diode laser absorption spectrometer (model TGA100A, Campbell Scientific, Logan, UT), referred to hereafter as a TDLAS, was used to make $\mathrm{N}_{2} \mathrm{O}$ gradient measurements that could be compared among multiple sites. It has been previously deployed for measuring $\mathrm{N}_{2} \mathrm{O}$ emissions in croplands (Laville et al., 1999; Wagner-Riddle et al., 2007; Wagner-Riddle and Thurtell, 1998), turf grass (Maggiotto et al., 2000) and irrigated pasture in Australia and New Zealand (Phillips et al., 2007; Harvey et al., 2008). A 
thorough description of the measurement of $\mathrm{N}_{2} \mathrm{O}$ gradients and the use of the flux gradient approach to determine $\mathrm{N}_{2} \mathrm{O}$ fluxes is given by Pattey et al. (2006).

In this study, we use the aerodynamic flux gradient method where the flux of a gas, $F_{\mathrm{g}}$, can be determined from the product of its vertical gradient above the surface of interest, $\left(\partial C_{\mathrm{g}} / \partial z\right)$ and an eddy diffusivity term, $K_{\mathrm{g}}$ :

$F_{\mathrm{g}}=-K_{\mathrm{g}}\left(\partial C_{\mathrm{g}} / \partial z\right)$

$K_{\mathrm{g}}$ is estimated using Monin-Obukhov similarity theory, which posits that under neutral conditions the turbulent diffusivities for momentum $\left(K_{\mathrm{m}}\right)$, heat $\left(K_{\mathrm{h}}\right)$ and gas $\left(K_{\mathrm{g}}\right)$ are equal (i.e. $K_{\mathrm{g}}=K_{\mathrm{m}}=K_{\mathrm{h}}$ ) (Monteith and Unsworth, 1990). Under non-neutral conditions, corrections can be made to equate the diffusivities (e.g. Högström, 1988). A tracer study by Flesch et al. (2002) indicating that $K_{\mathrm{m}}$ may be only 0.6 of $K_{\mathrm{g}}$ has challenged this concept of equal diffusivities under neutral conditions, and we address this issue in the discussion section. Measurements of the three-dimensional wind field and virtual temperature are made with a sonic anemometer, and can be used to estimate a value for $K_{\mathrm{g}}$ that we assume applies to the entire field over the gradient sampling time. The gradient, $\left(\partial C_{\mathrm{g}} / \partial z\right)$, can be measured at points upwind of the treatment plots of interest.

The set-up was designed so that it could be deployed in a commercial livestock grazing system with the capability to compare emissions from up to five 1.5 ha plots, but is particularly suited for the comparing up to two mitigation or $\mathrm{N}$-manipulation treatments with an untreated control.

\subsection{Set-up of experimental field for testing of the FS-NOMAS}

We tested the FS-NOMAS at an intensively managed, commercial dairy farm $6 \mathrm{~km}$ southwest of the Methven Township in Canterbury, New Zealand (Fig. 1). The field was located at $43^{\circ} 40^{\prime} \mathrm{S}, 171^{\circ} 35^{\prime} \mathrm{E}$ at an altitude of $308 \mathrm{~m}$. The area has an annual average temperature of $11.1^{\circ} \mathrm{C}(2009-2011)$ and a total mean annual precipitation of $978 \mathrm{~mm} \mathrm{yr}^{-1}$ (19812010) (retrieved from the National Institute of Water and Atmosphere's Climate Database: http://cliflo.niwa.co.nz/). A centre-pivot irrigator was used to supplement rainfall to achieve a total water application rate of $6 \mathrm{~mm} \mathrm{~d}^{-1}$ during summer. The soil is a well-drained sedimentary Pallic Firm Brown Soil described as a Lismore Stony Silt Loam (Hewitt, 1988).

The North end of a 10 ha paddock was subdivided crosswise into five equal size plots of dimensions $100 \mathrm{~m} \times 155 \mathrm{~m}$ - the shorter edge oriented in the NNW direction $\left(338^{\circ}\right)$, and the longer edge oriented in the ENE $\left(68^{\circ}\right)$ direction (Fig. 1). Four short $(2 \mathrm{~m})$ masts, equipped with air intakes were located at the centre point of each of the four common edges of the five plots. The wind regime was largely bi-directional. During northerly winds, the towers sampled fluxes from the

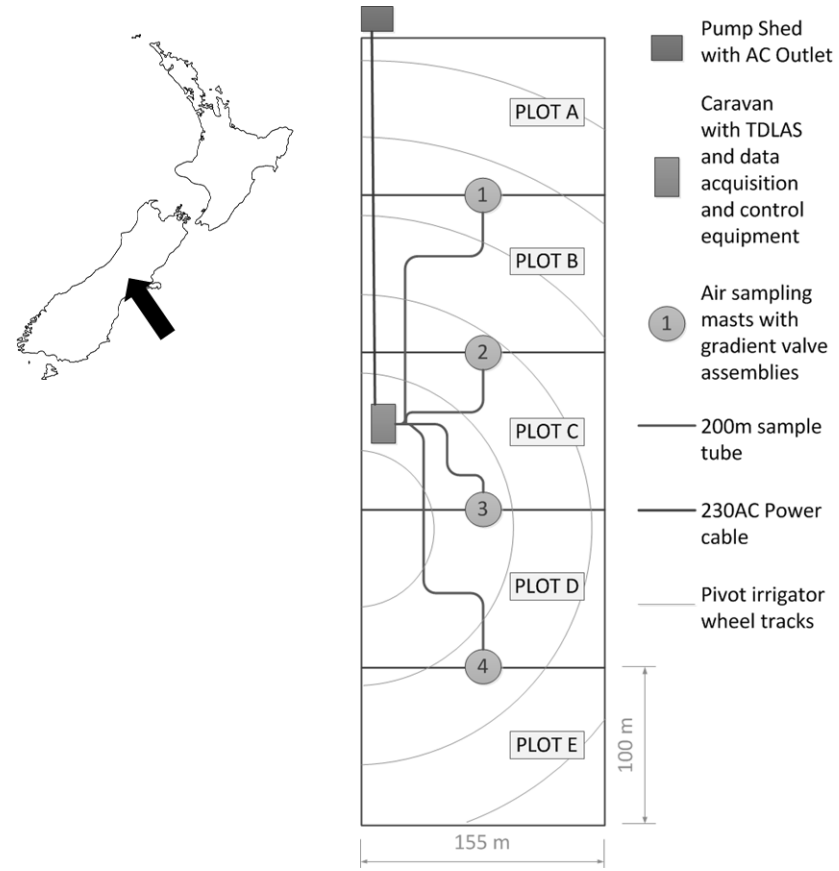

Fig. 1. Location of experimental site near Methven, Canterbury, New Zealand, where the FS-NOMAS was deployed (left panel). Field plan of sampling equipment showing field dimensions, layout of sampling masts relative to the TDLAS analyser and the AC power source (right panels). The gradient generated by the fluxes from each plot is measured by the most immediately adjacent and downwind mast. For example, fluxes from plot $\mathrm{C}$ are measured at mast 3 during a northerly wind and at mast 2 during a southerly wind.

adjacent plot in the northerly direction. During southerly winds, each tower sampled fluxes from plots to the south.

This configuration (Fig. 1) allowed the possible testing of different treatments on plots $\mathrm{B}$ and $\mathrm{D}$, while the remaining plots (A, C and $\mathrm{E})$ acted as experimental control plots. Two trials were conducted using several different nitrogen management techniques to test the ability of the FS-NOMS in determining treatment effects on $\mathrm{N}_{2} \mathrm{O}$ fluxes. In the Autumn Experiment (1 May 2010-22 June 2010) we tested the ability of the FS-NOMAS to distinguish between recently grazed paddocks that were spray treated with $10 \mathrm{~kg} \mathrm{ha}^{-1}$ of a suspension form of the nitrification inhibitor, dicyandiamide (DCD). In the Spring Experiment (20 September 201025 November 2010), the FS-NOMAS was tested using plot treatments of (a) $10 \mathrm{~kg} \mathrm{ha}^{-1}$ of granular form of DCD in one plot and (b) a doubled urea-N application $\left(60 \mathrm{~kg} \mathrm{ha}^{-1}\right.$ versus $30 \mathrm{~kg} \mathrm{ha}^{-1}$ that was applied to control plots and DCD plot).

\subsection{Sample collection and analysis of the $\mathrm{N}_{2} \mathrm{O}$ gradient, $\Delta \mathbf{N}_{2} \mathrm{O}$}

The plumbing system of FS-NOMAS consisted of gradient valve assemblies (GVAs) installed on each of the four masts 


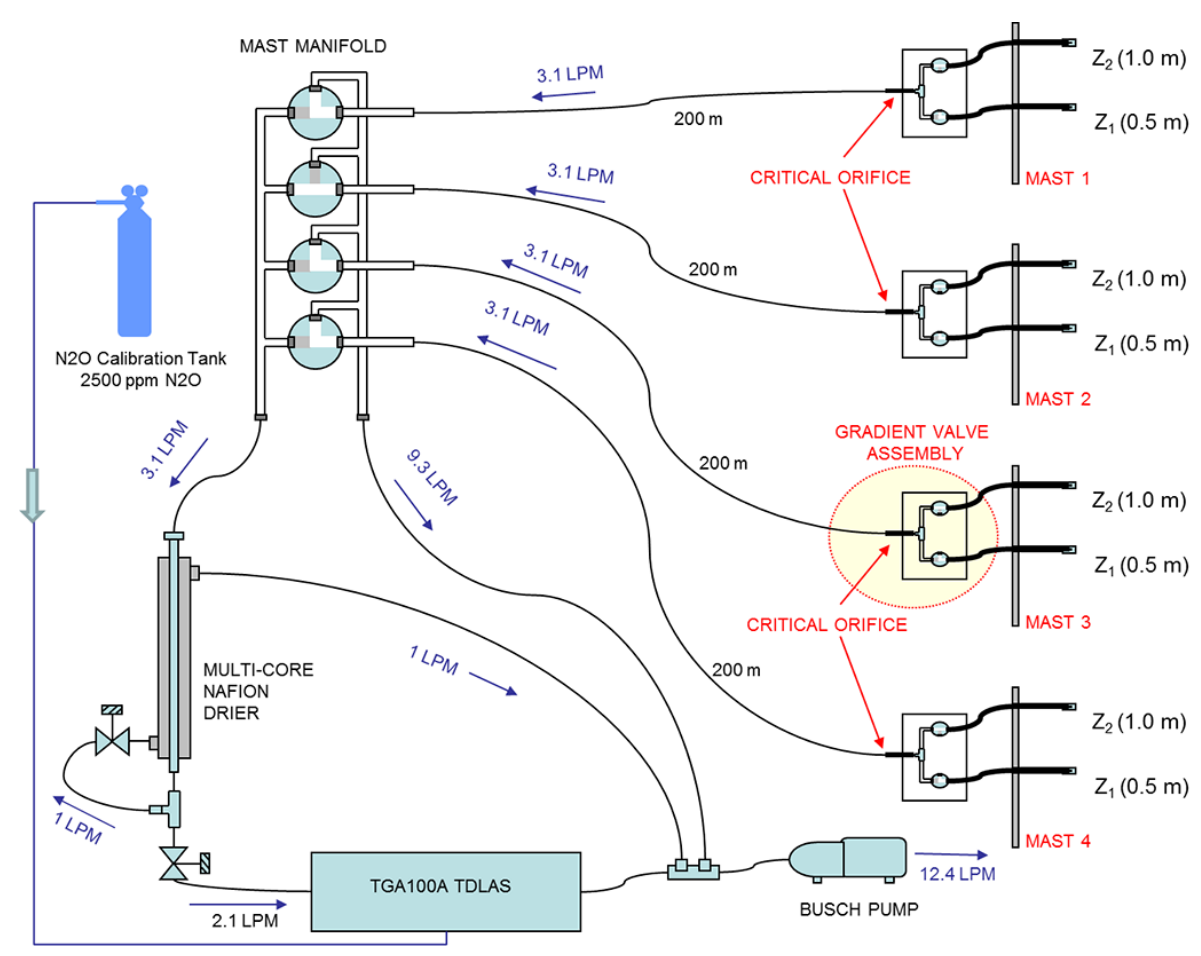

Fig. 2. Schematic diagram of FS-NOMAS plumbing. Each gradient valve assembly selects air from either inlet $z_{1}$ and $z_{2}$ every 6 or $9 \mathrm{~s}$. All air streams are routed towards the Busch pump. One of the four air streams is diverted through the Nafion drier and the TDLAS for $\mathrm{N}_{2} \mathrm{O}$ analysis. Every 20 or 30 min the mast sampling manifold switches so that another air stream is analysed. The $\mathrm{N}_{2} \mathrm{O}$ signal in the TDLAS sample cell is continuously referenced to the signal of the reference cell that is continuously flushed with the $\mathrm{N}_{2} \mathrm{O}$ calibration gas.

connected to a common sample manifold via separate $200 \mathrm{~m}$ lengths of $6.35 \mathrm{~mm}$ i.d. polythene tube (Fig. 2). Each GVA consisted of two solenoid valves that alternately connected inlets $z_{1}$ or $z_{2}$ in line with the $200 \mathrm{~m}$ tube. The GVA was equipped with a $0.6 \mathrm{~mm}$ diameter critical orifice (O'Keefe Controls, Trumbull, CT) that choked flow to $3.1 \mathrm{~L} \mathrm{~min}^{-1}$ and prevented condensation of water within the tube by maintaining sub-ambient pressure en route to the TDLAS.

The sample manifold could be set to connect any one of the four GVAs to the TDLAS via a multi-core Nafion ${ }^{\circledR}$ membrane drier (PD1000 Series, Campbell Scientific Inc., Logan, UT) and air collected from the three other GVAs to bypass the TDLAS and drier and flow directly to the vacuum pump. The vacuum was achieved by a rotary-vane pump (Busch 0021, Busch USA, Virginia Beach, VA, USA).

The TDLAS was tuned to a single mid-infrared absorbance line and was controlled precisely for laser temperature and current (Table 2). Throughout the measurement sequence, the TDLAS measurement cell was maintained at an absolute pressure of $5 \mathrm{kPa}$.

Measurements of $\mathrm{N}_{2} \mathrm{O}$ mole fraction were made on the airstream exiting the particular $200 \mathrm{~m}$ tube that was in line the TDLAS during a sampling interval. $\mathrm{N}_{2} \mathrm{O}$ mole fraction data was acquired at a rate of $10 \mathrm{~Hz}$. This airstream consisted of discrete packets of air that resulted from the alternating sampling of inlets $z_{1}$ and $z_{2}$ at the GVA. The two heights at which the gradient was measured, $z_{1}=0.5 \mathrm{~m}$ and $z_{2}=1.0 \mathrm{~m}$, were fixed throughout the study so that there was a constant relationship between the $\mathrm{N}_{2} \mathrm{O}$ gradient (ppb/height) and the measured $\Delta \mathrm{N}_{2} \mathrm{O}$ (ppb between $z_{1}$ and $z_{2}$ ). Accordingly, the term $\Delta \mathrm{N}_{2} \mathrm{O}$ refers to the $\mathrm{N}_{2} \mathrm{O}$ mole fraction difference measured between $z_{1}$ and $z_{2}$. $\mathrm{N}_{2} \mathrm{O}$ mole fractions could be assigned to each inlet based on knowledge of the transit time from the inlets to the TDLAS. This transit time from the inlets to the TDLAS was estimated by introducing a pulse of liquid nitrogen vapour (depleted in $\mathrm{N}_{2} \mathrm{O}$ ) to the inlet and measuring the time until a response at the TDLAS was observed (Pattey et al., 2006). This estimate of transit time was refined during post-processing of the data.

Having corrected for the transit time, the $\mathrm{N}_{2} \mathrm{O}$ signal from the air stream was organised into two data sets according to whether the air was collected from $z_{1}$ or $z_{2}$. Data corresponding to the inlet transition period $1.5 \mathrm{~s}$ immediately before and the $1 \mathrm{~s}$ immediately after the GVA switched between inlets were omitted from each data set.

Two different valve timing schemes were tested (Table 1). In the Autumn Experiment, the GVA switched between $z_{1}$ and $z_{2}$ every $9 \mathrm{~s}$ and repeated the sequence 100 times before the manifold connected a GVA at another mast in line with the sensor. This resulted in a sampling time of $30 \mathrm{~min}$ at each mast. In the Spring Experiment, the switching time was 
Table 1. Valve timings of the GVA and mast manifold and associated precision of the $\Delta \mathrm{N}_{2} \mathrm{O}$ measurement.

\begin{tabular}{lll}
\hline Parameter & $\begin{array}{l}\text { Autumn } \\
\text { experiment }\end{array}$ & $\begin{array}{l}\text { Spring } \\
\text { experiment }\end{array}$ \\
\hline Sample integration time & $9 \mathrm{~s}$ & $6 \mathrm{~s}$ \\
Time for a single comparison of $z_{1}$ and $z_{2}$ & $18 \mathrm{~s}$ & $12 \mathrm{~s}$ \\
Number of comparisons per mast & 100 & 100 \\
Mast sampling interval & $1800 \mathrm{~s}(30 \mathrm{~min})$ & $1200 \mathrm{~s}(20 \mathrm{~min})$ \\
Number of measurements at each mast per day & 12 & $18 \mathrm{~s}$ \\
Sample expected value of $\mathrm{SE} \Delta \mathrm{N}_{2} \mathrm{O}(\mathrm{ppb})$ integration time & $9 \mathrm{~s}$ & $6 \mathrm{~s}$ \\
Expected value of $\mathrm{SE}_{\Delta \mathrm{N}_{2} \mathrm{O}}(\mathrm{ppb})$ & 0.024 & 0.023 \\
\hline
\end{tabular}

Table 2. Operating parameters of the TDLAS.

\begin{tabular}{ll}
\hline Parameter & Value \\
\hline Laser temperature & $93.2 \mathrm{~K}$ \\
Laser current & $850 \mathrm{~mA}$ \\
Emission frequency & $2208.691 \mathrm{~cm}^{-1}$ \\
Sample cell volume & $0.48 \mathrm{~L}$ \\
Flow through sample cell & $2.1 \mathrm{~L} \mathrm{~min}^{-1}$ \\
Sample cell residence time & $0.67 \mathrm{~s}$ \\
\hline
\end{tabular}

reduced to $6 \mathrm{~s}$, and with 100 repetitions of the $z_{1} / z_{2}$ cycle resulted in a mast sampling time of $20 \mathrm{~min}$.

When measuring $\mathrm{N}_{2} \mathrm{O}$ at more than one location (and using a single sample pump), the flow must be split among all the four sample lines (the one in line with the TDLAS and the three others that are bypassing the laser, see Fig. 2). This resulted in a reduced flow through the sample cell $\left(2.1 \mathrm{~L} \mathrm{~min}^{-1}\right)$, which in turn increased the residence time within the sample cell to $0.67 \mathrm{~s}$. This reduced the effective response time of the instrument below that of the $10 \mathrm{~Hz}$ data acquisition rate. However, the sampling frequency was still sufficiently high to obtain a precise estimate of $\mathrm{N}_{2} \mathrm{O}$. For the $9 \mathrm{~s}$ switching time in the Autumn Experiment, 977 independent samples of $\mathrm{N}_{2} \mathrm{O}$ from each height were obtained. For the $6 \mathrm{~s}$ switching time in the Spring Experiment, 451 independent samples of $\mathrm{N}_{2} \mathrm{O}$ from each height were obtained.

The estimate of the uncertainty or error to which $\Delta \mathrm{N}_{2} \mathrm{O}$ was determined was calculated from the standard error of the difference between two means (Zar, 1984):

$\mathrm{SE}_{\Delta \mathrm{N}_{2} \mathrm{O}}=\sqrt{\frac{\sigma_{z_{1}}^{2}}{n_{z_{1}}}+\frac{\sigma_{z_{2}}^{2}}{n_{z_{2}}}}$

where $\sigma_{z_{1}}^{2}$ and $\sigma_{z_{2}}^{2}$ are the pooled variances of the individual $\mathrm{N}_{2} \mathrm{O}$ determinations for the upper and lower inlets, $z_{1}$ and $z_{2}$, respectively. The $\mathrm{SE}_{\Delta \mathrm{N}_{2} \mathrm{O}}$ was calculated for each measurement interval resulting in 4371 determinations of this statistic during the two experiments.

The statistical significance of an observed $\Delta \mathrm{N}_{2} \mathrm{O}$ value was assessed by comparing the Student's $t$ value of a gradient, $t=\Delta \mathrm{N}_{2} \mathrm{O} / \mathrm{SE}_{\Delta \mathrm{N}_{2} \mathrm{O}}$, against the one-tailed critical
Student's $t$ value with the number of degrees of freedom corresponding to the number of independent $\mathrm{N}_{2} \mathrm{O}$ determinations.

\subsection{Laboratory determination of gradient resolution}

A verification test, using fixed volumes spiked with $\mathrm{N}_{2} \mathrm{O}$, was designed to confirm that the FS-NOMAS was capable of (i) transporting packets of air collected at the inlets in an intact form to the TDLAS; (ii) that the $\mathrm{N}_{2} \mathrm{O}$ between inlets $z_{1}$ and $z_{2}$ were accurately measured, and (iii) that very small values of $\mathrm{N}_{2} \mathrm{O}$ could be adequately resolved. In principle, if we had the ability to create two calibration tanks that have very small differences in $\mathrm{N}_{2} \mathrm{O}$ mole fraction we could test this directly. However, in practice, making and calibrating gas mixtures with small mole fraction differences (below $1 \mathrm{ppb}$ ) level is laborious. Further, even if this was achieved, the large flow requirement of the sampling system (3.1 $\mathrm{L} \mathrm{min}^{-1}$ ) would mean that any such tanks, once created, would be rapidly exhausted.

Instead, we compared the $\mathrm{N}_{2} \mathrm{O}$ content of two air streams using the set-up shown in Fig. 3. The first air stream was extracted from a fixed ballast volume $(60 \mathrm{~L})$ that was continually flushed with ambient air. The second air stream was also a continually flushed fixed ballast volume $(60 \mathrm{~L})$, and at a point in time was spiked with a dose of concentrated $\mathrm{N}_{2} \mathrm{O}$. Immediately following the spiking, the mole fraction difference between the two air streams was high $(\sim 14 \mathrm{ppb})$. With continued flushing the mole fraction difference between the barrels decreased due to dilution of air in the second barrel with fresh ambient air. The time course of the mole fraction decrease followed a negative exponential function that was predictable using a first-order exponential decay equation using the initial $\mathrm{N}_{2} \mathrm{O}$ spike amount and the residence time of air in the barrel as parameters. Over time, the $\mathrm{N}_{2} \mathrm{O}$ difference between the two air streams became negligible. Just before this occurred, in the final stages of the exponential decay, there was a period of time during which the $\mathrm{N}_{2} \mathrm{O}$ difference between the two air streams was extremely small. It was during this period that we could examine the limits of the instrument to resolve gradients of $\mathrm{N}_{2} \mathrm{O}$. 


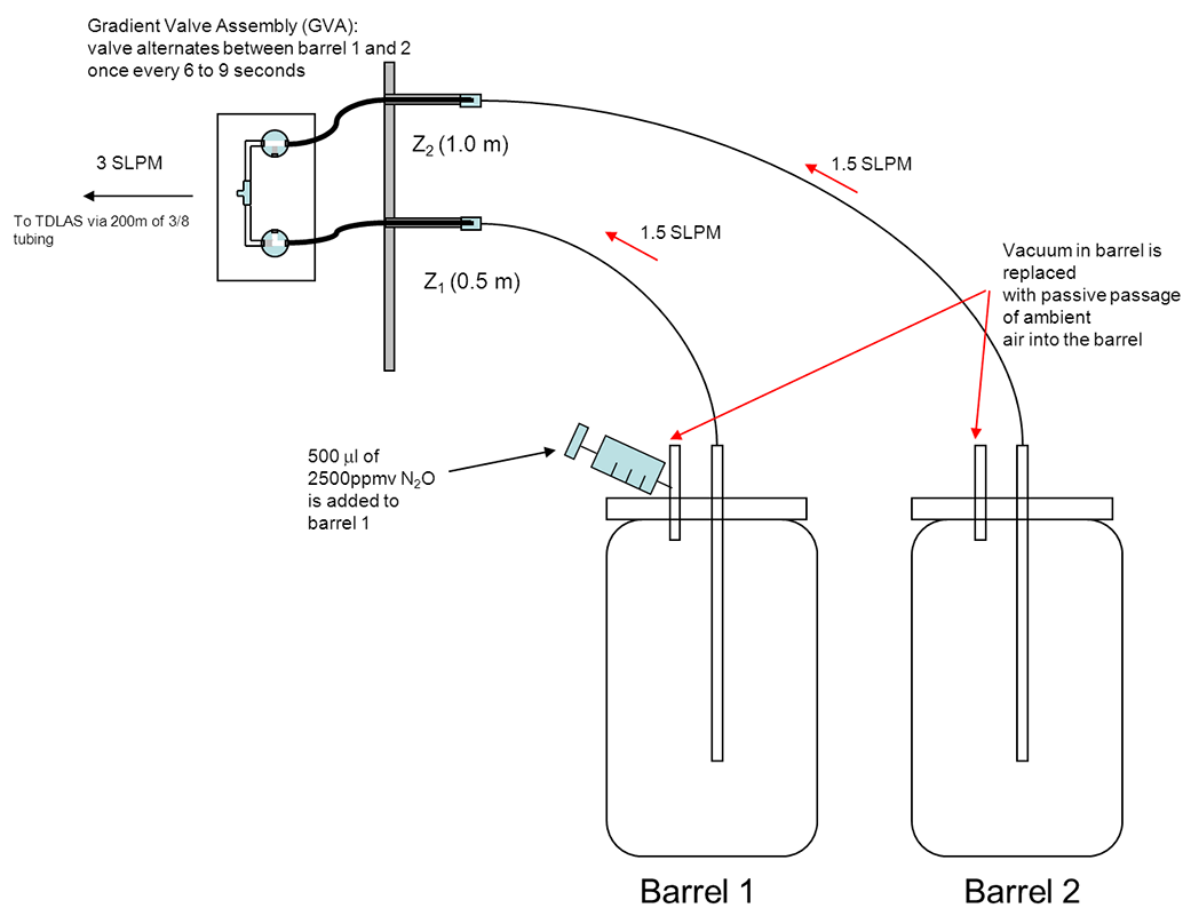

Fig. 3. Method to determine minimum resolution of $\mathrm{N}_{2} \mathrm{O}$ gradient using $60 \mathrm{~L}$ ballast volumes.

The two air streams were achieved by attaching two $60 \mathrm{~L}$ plastic barrels to the inlets $z_{1}$ and $z_{2}$ of the GVA. The barrels were capped with an airtight seal. The caps had two sampling ports that allowed attachments of tubes to the internal volume of the barrel. One port was attached to the sample inlet of the GVA, while the other port was left open.

This set-up closely approximated field sampling conditions. The remaining three GVAs (those not attached to the barrels) were also in the same configuration as in the field, whereby they continued alternating between $z_{1}$ and $z_{2}$, but the sampled air bypassed the Nafion drier and the TDLAS, and went directly to the pump.

The $\mathrm{N}_{2} \mathrm{O}$ trace from the TDLAS was measured for approximately $1 \mathrm{~h}$ to establish that there was a minimal difference between the two barrels. Then one of the barrels was injected with $0.5 \mathrm{~mL}$ of a $\mathrm{N}_{2} \mathrm{O}$ calibration mixture that had a mole fraction of $2500 \mathrm{ppb}$ (BOC Special Gases, gravimetrically prepared according to ISO6143 gas analysis methods). The $1250 \mathrm{~nL}$ aliquot of $\mathrm{N}_{2} \mathrm{O}$ increased the $\mathrm{N}_{2} \mathrm{O}$ mole fraction of the $z_{1}$ barrel by $\sim 14 \mathrm{ppb}$ relative to the other barrel. However, this elevation was short lived, and decayed away (over $\sim 5 \mathrm{~min}$ ) as fresh ambient air was continually drawn into both barrels (from the same height) at an average rate of $1.5 \mathrm{~L} \mathrm{~min}^{-1}$.

An examination of repeated $\mathrm{N}_{2} \mathrm{O}$ (elevation above ambient) determinations indicated that the packets of air alternately sampled from the two inlets remained intact during the $200 \mathrm{~m}$ transit to the TDLAS (see Fig. 2), which allowed for the precise quantification of the $\mathrm{N}_{2} \mathrm{O}$ mole fraction difference between $z_{1}$ and $z_{2}, \Delta \mathrm{N}_{2} \mathrm{O}$. The $\Delta \mathrm{N}_{2} \mathrm{O}$ closely followed the $\mathrm{N}_{2} \mathrm{O}$ predicted from a consideration of the exponential decay dilution of the added $\mathrm{N}_{2} \mathrm{O}$ (Fig. 4) with fresh ambient air at a rate of $1.56 \mathrm{~L} \mathrm{~min}^{-1}$. Following the injection, the $\mathrm{N}_{2} \mathrm{O}$ mole fraction in the spiked barrel would decrease in an exponential manner according to the decay function below:

$\Delta \mathrm{N}_{2} \mathrm{O}_{\text {pred }}(t)=c \mathrm{e}^{-b t}$,

where $\Delta \mathrm{N}_{2} \mathrm{O}_{\text {pred }}$ is the mole fraction difference between the barrels at time $t$ ( $\min )$ following the injection, $\quad b=$ flow through barrel/barrel volume $\left(1.56 \mathrm{~L} \mathrm{~min}^{-1} / 60 \mathrm{~L}=0.026 \mathrm{~min}^{-1}\right)$ and $c=\mathrm{N}_{2} \mathrm{O}$ injected (1250 nL).

We compared the agreement between observed $\Delta \mathrm{N}_{2} \mathrm{O}$ and $\Delta \mathrm{N}_{2} \mathrm{O}_{\text {pred }}$ for $5.1 \mathrm{~h}$ following the injection. The correspondence was highly significant $\left(\Delta \mathrm{N}_{2} \mathrm{O}=0.999 \Delta \mathrm{N}_{2} \mathrm{O}_{\text {pred }}-0.0922, r^{2}=0.999, \quad P<0.01\right)$ and indicated that the accuracy of the FS-NOMAS in determining $\Delta \mathrm{N}_{2} \mathrm{O}$ differences was satisfactory over periods longer than the 20-30 min site sampling duration for a wide range of $\Delta \mathrm{N}_{2} \mathrm{O}$.

Finally, after $5.1 \mathrm{~h}$ of dilution, the mole fraction of the spiked barrel was only very slightly greater than that of the unspiked barrel $\left(\Delta \mathrm{N}_{2} \mathrm{O}=0.058 \pm 0.019 \mathrm{ppb}\right.$, Fig. 4) yet this was a statistically significant difference $(P<0.005)$ and indicated that the FS-NOMAS was capable of resolving extremely small values of $\mathrm{N}_{2} \mathrm{O}$. 


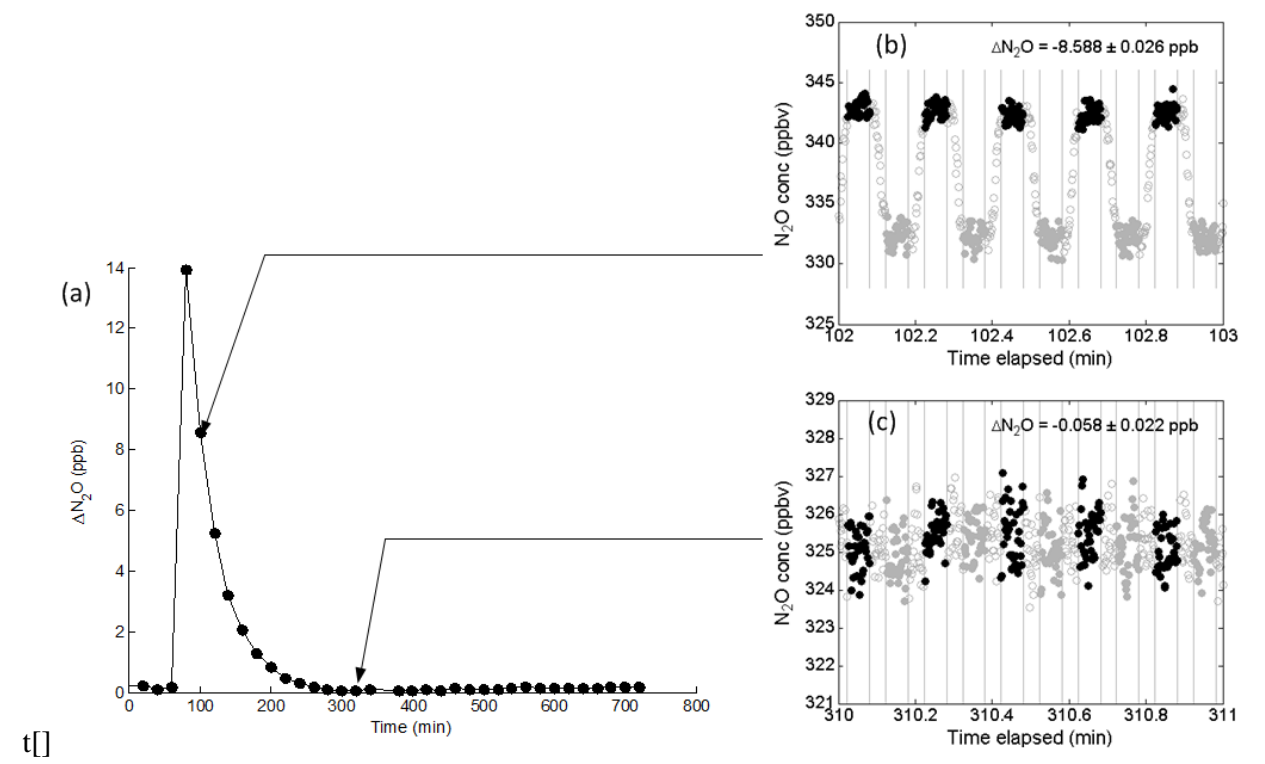

Fig. 4. Test of FS-NOMAS accuracy and resolution using "spiked" barrel approach. (a) Difference in $\mathrm{N}_{2} \mathrm{O}$ mole fraction $\left(\Delta \mathrm{N}_{2} \mathrm{O}\right)$ between spiked and unspiked barrels. Spiking of $1250 \mathrm{~nL}$ of pure $\mathrm{N}_{2} \mathrm{O}$ into a $60 \mathrm{~L}$ barrel occurred at $100 \mathrm{~min}$. Time series of $10 \mathrm{~Hz} \mathrm{~N}_{2} \mathrm{O}$ determinations at $102 \mathrm{~min}$ (b) and $310 \mathrm{~min}$ (c), where solid points represent $\mathrm{N}_{2} \mathrm{O}$ measured at heights of $0.5\left(z_{1}\right.$, black circles) and $1.0 \mathrm{~m}\left(z_{2}\right.$, grey circles). Data affected by valve switching between $z_{1}$ and $z_{2}$ (open circles) are omitted.

\subsection{Calculation of the $\mathrm{N}_{2} \mathrm{O}$ flux, $F_{\mathrm{N}_{2} \mathrm{O}}$}

The form of the equation used for the calculation of fluxes (Eq. 4) contains the term $C_{\mathrm{Tr}}$, which incorporates both the molar density of air and the stability-corrected diffusivity integrated over the height interval of interest:

$F_{\mathrm{N}_{2} \mathrm{O}}=100.8 \times C_{\mathrm{Tr}} \times \Delta \mathrm{N}_{2} \mathrm{O}$,

where $C_{\text {Tr }}$ is the transfer coefficient $\left(\mathrm{mol}_{\mathrm{Air}} \mathrm{m}^{-2} \mathrm{~s}^{-1}\right), \Delta \mathrm{N}_{2} \mathrm{O}$ is the $\mathrm{N}_{2} \mathrm{O}$ mole fraction difference $\left(\mathrm{nmol} \mathrm{mol}^{-1}\right)$ over the vertical distance between the air sample inlets, $z_{2}-z_{1}$, and 100.8 is a conversion factor to convert $\mathrm{nmol} \mathrm{N}_{2} \mathrm{O} \mathrm{m}^{-2} \mathrm{~s}^{-1}$ to $\mu \mathrm{g} \mathrm{N} \mathrm{N}_{2} \mathrm{O}-\mathrm{N} \mathrm{m}^{-2} \mathrm{~h}^{-1}$. The rationale for introducing the term $C_{\operatorname{Tr}}$ is to provide a single proportionality factor between gradient and the flux that is specific to a particular set of measurement heights and incorporates both the stability correction and the density of air. It allowed a simple assessment of the relative importance of the emission rate versus the turbulent/advective conditions of the atmosphere in determining the $\mathrm{N}_{2} \mathrm{O}$ gradient measured at the mast:

$C_{\operatorname{Tr}}\left(\mathrm{mol}_{\text {Air }} \mathrm{m}^{-2} \mathrm{~s}^{-1}\right)=\rho_{\mathrm{a}} \times D_{\mathrm{a}}$,

where $\rho_{\mathrm{a}}$ is the molar density of air $\left(\operatorname{mol}_{\text {Air }} \mathrm{m}^{-3}\right)$ and $D_{\mathrm{a}}$ is the diffusion velocity (Miyata et al., 2000):

$D_{\mathrm{a}}\left(\mathrm{ms}^{-1}\right)=k u_{*} / J$,

where $k$ is von Kármán's constant $(0.40)$ and $u_{*}$ is the friction velocity. The friction velocity $u_{*}$ is calculated by

$u_{*}\left(\mathrm{~ms}^{-1}\right)=\left[\left\langle u^{\prime} v^{\prime}\right\rangle^{2}+\left\langle v^{\prime} w^{\prime}\right\rangle^{2}\right]^{0.25}$, where $u^{\prime}, v^{\prime}$ and $w^{\prime}$ are the instantaneous fluctuations in the streamwise, crosswind and vertical wind components, measured by the sonic anemometer. The term $J$ in the denominator of Eq. (6) combines the heights of the air inlets and the corrections to the stability parameters:

$$
\begin{aligned}
J & =\left[\ln \left(z_{2}-d\right)-\Psi_{\mathrm{h}}\left(\left(z_{2}-d\right) / L\right)\right] \\
& -\left[\ln \left(z_{1}-d\right)-\Psi_{\mathrm{h}}\left(\left(z_{1}-d\right) / L\right)\right],
\end{aligned}
$$

where

$\Psi_{\mathrm{h}}\left(\left(z_{2}-d\right) / L\right)=2 \ln ((1+y) / 2)$ for $(z-d) / L<0$,

and

$\left.\Psi_{\mathrm{h}}\left(\left(z_{2}-d\right) / L\right)=-7.8(z-d) / L\right)$ for $(z-d) / L \geq 0$

where $y=0.95(1-11.6((z-d) / L))$ after Högström (1988) and Paulson (1970). The term $d$ represents zero plane displacement height (calculated as 0.66 of the canopy height), and must be subtracted from the measuring height $(z)$ to represent the aerodynamic height (Foken, 2008). $L$ is the Obukhov length representing the balance between mechanical and convective turbulence:

$L=\frac{-u_{*}^{3} \theta_{\mathrm{v}}}{k g\left\langle w^{\prime} \theta_{\mathrm{v}}^{\prime}\right\rangle}$,

where $g$ is the gravitational constant, $\theta_{\mathrm{v}}$ is the mean virtual temperature and $\left\langle w^{\prime} \theta_{\mathrm{v}}^{\prime}\right\rangle$ is the virtual temperature flux. The quantities $u^{\prime}, v^{\prime}, w^{\prime},\left\langle w^{\prime} \theta_{\mathrm{v}}^{\prime}\right\rangle$ and $u_{*}$ required for $C_{\operatorname{Tr}}$ and $L$ were measured by two sonic anemometers (CSAT3, Campbell Scientific, Logan, UT, and WindMasterPro, Gill Instruments, Lymington, UK) located at mast 2 and 3. 


\section{Results}

\subsection{Instrument signal characteristics and determination of $\mathrm{N}_{2} \mathrm{O}$}

Optimal performance of the TDLAS is achieved when it is used to measure relative, rather than absolute, mole fraction measurements (Edwards et al., 1994). The raw $\mathrm{N}_{2} \mathrm{O}$ mole fraction signal was acquired from the TDLAS at a frequency of $10 \mathrm{~Hz}$ and varied by $0.8 \mathrm{ppb}$ (standard deviation) over a $12 \mathrm{~s}$ integration period. The signal was also subject to drift over longer time scales due to small, temperature-driven interferences in the optical path of the instrument, caused by a phenomenon known as the Fabry-Perot effect (Edwards et al., 1994). Operating the instrument in a relative mode and making many repeated comparisons of the $\mathrm{N}_{2} \mathrm{O}$ mole fraction at $z_{1}$ and $z_{2}$ (following the approach described in Pattey et al., 2006) optimised the instrument's ability to resolve $\mathrm{N}_{2} \mathrm{O}$.

The performance of the FS-NOMAS in measuring $\mathrm{N}_{2} \mathrm{O}$ under ambient field conditions was assessed during the $\mathrm{Au}-$ tumn and Spring Experiments of 2010 at Methven. An example of a $\mathrm{N}_{2} \mathrm{O}$ time series collected during a single sampling period indicated that dominant modes of variability occur both on short $(<10 \mathrm{~s})$ and longer $(>10 \mathrm{~s})$ timescales (Fig. 5a). The shorter-term variability is associated with random instrumental noise, while the longer-term drift is associated with variations in ambient $\mathrm{N}_{2} \mathrm{O}$ mole fraction and the optical fringing that occurs due to the Fabry-Perot effect described above. Allan variance analysis (Allan, 1966) is useful for depicting the signal variance as a function of integration times and has been used to determine appropriate integration times for laser signals (Hendriks et al., 2008; Mammarella et al., 2010). Allan variance analysis on the TDLAS signal indicated that the optimal time over which to average the $\mathrm{N}_{2} \mathrm{O}$ signal is 6 to $10 \mathrm{~s}$ in order to minimise the influence of both short-term and long-term variability (Fig. 5b).

The choice of the sample time, together with the choice of the number of $\mathrm{N}_{2} \mathrm{O}$ determinations per sampling interval, dictated how many sampling intervals per mast could be achieved in a $24 \mathrm{~h}$ period. We tested sampling times of $9 \mathrm{~s}$ (Autumn Experiment) and 6s (Spring Experiment). The $6 \mathrm{~s}$ sampling time was optimal (see Sect. 3.3) and consisted of $6 \mathrm{~s}$ of $\mathrm{N}_{2} \mathrm{O}$ determinations from air collected at $z_{1}$ followed by $6 \mathrm{~s}$ of measurement at $z_{2}$. This comparison interval of $12 \mathrm{~s}$ was repeated 100 times, resulting in a $20 \mathrm{~min}$ (1200 s) sampling interval for each mast. Accordingly, each mast was sampled 18 times a day. Figure 5c shows a time series of 100 consecutive $12 \mathrm{~s}$ comparisons plotted on a 0 to $12 \mathrm{~s}$ axis. Within each $6 \mathrm{~s}$ interval only measurements from 1.5 to $4.5 \mathrm{~s}$ were accepted for analysis, the remainder being omitted to avoid the possibility of cross-contamination between adjacent packets in the tube connection the inlets with the TDLAS. Over the $1200 \mathrm{~s}$, the data set of 451 independent $\mathrm{N}_{2} \mathrm{O}$ determinations from each inlet were obtained,
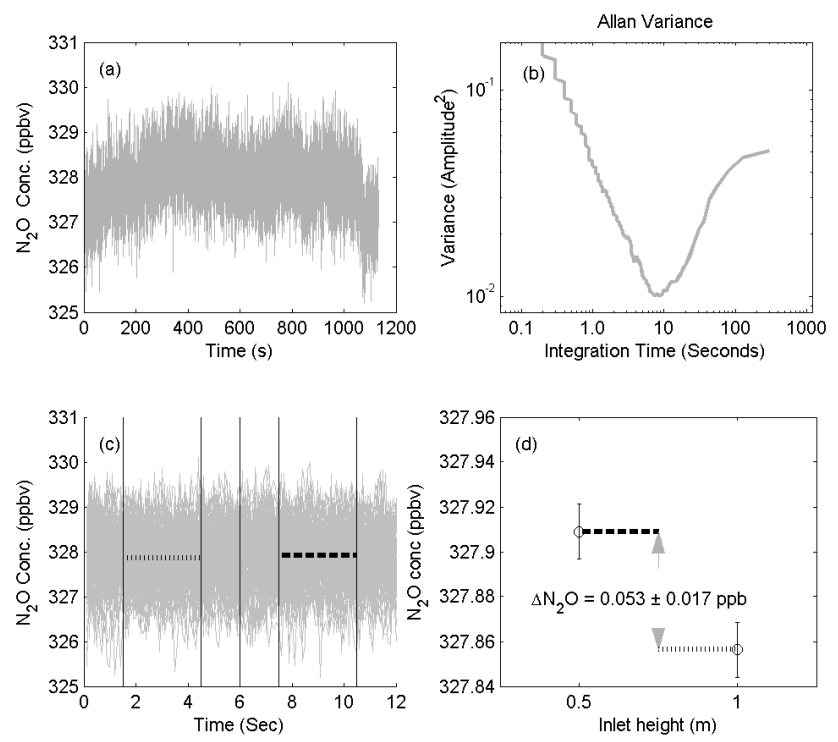

Fig. 5. (a) Example of a $1200 \mathrm{~s}$ time series of $10 \mathrm{~Hz} \mathrm{~N} \mathrm{~N}_{2} \mathrm{O}$ determinations measured by the $\mathrm{N}_{2} \mathrm{O}$ analyser (TDLAS), which was integrated within the FS-NOMAS; (b) Allan variance as a function of averaging time; (c) the $1200 \mathrm{~s}$ time series folded into 100 sequential $12 \mathrm{~s}$ time series where the dashed and dotted lines designate the average $\mathrm{N}_{2} \mathrm{O}$ mole fraction measured at $0.5 \mathrm{~m}\left(z_{1}\right)$ and $1.0 \mathrm{~m}\left(z_{2}\right)$ heights, respectively; (d) average and standard deviation of the $\mathrm{N}_{2} \mathrm{O}$ determinations for each height and calculated $\Delta \mathrm{N}_{2} \mathrm{O}\left( \pm \mathrm{SE}_{\Delta \mathrm{N}_{2} \mathrm{O}}\right)$. Vertical error bars indicate the normal distribution with $\mu=$ average $\mathrm{N}_{2} \mathrm{O}$ mole fraction and $\sigma=$ standard deviation for the populations of $\mathrm{N}_{2} \mathrm{O}$ determinations collected at each height.

allowing a $\mathrm{N}_{2} \mathrm{O}$ difference to be measured with 450 degrees of freedom (Fig. 5d). For the example shown in Fig. 5, the $\mathrm{N}_{2} \mathrm{O}$ ( \pm standard error of difference between two means) was $0.053 \pm 0.017 \mathrm{ppb}$ and was significant $(P<0.01)$.

\subsection{Gradient observations - values of $\mathrm{N}_{2} \mathrm{O}$ in ambient air and dependence on atmospheric mixing}

In this study, the overwhelming majority ( $>99 \%$ ) of the gradients were positive, indicating that flux was almost entirely in the upwards direction. None of the negative fluxes were statistically significant. Over the entire period of measurements, the largest ten gradients ranged between 15 and $88 \mathrm{ppb}$ and generally occurred under very stable conditions. The lowest ten gradients significant at $P<0.01$ ranged from 0.035 to $0.046 \mathrm{ppb}$. The most likely value for $\mathrm{N}_{2} \mathrm{O}$ was $0.058 \mathrm{ppb}$ (the peak value of the frequency distribution over all measurements of $\mathrm{N}_{2} \mathrm{O}$ ). $\mathrm{N}_{2} \mathrm{O}$ gradients are affected both by the rate of vertical mixing in the surface layer of the atmosphere and the source strength of the local fluxes. Therefore, when interpreting the magnitude of the observed $\mathrm{N}_{2} \mathrm{O}$ to infer flux strength, it is necessary to account for the atmospheric mixing, quantified here by the transfer coefficient, $C_{\mathrm{Tr}}$. Figure 6 shows individual frequency distributions of $\mathrm{N}_{2} \mathrm{O}$ and 

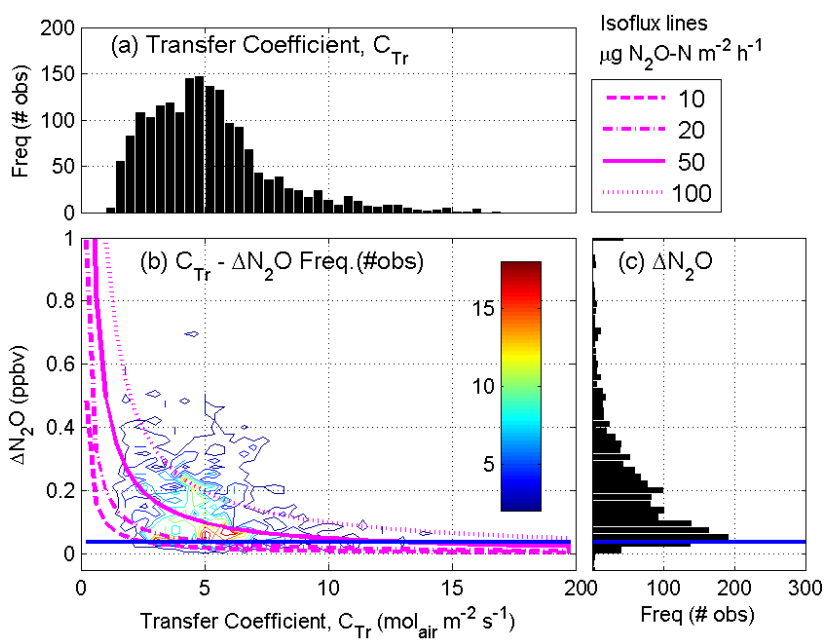

Fig. 6. Observation frequencies of $\Delta \mathrm{N}_{2} \mathrm{O}$ and $C_{\mathrm{Tr}}$ : separate histograms and combined contour plot. (a) Histogram of observations of the transfer coefficients, $C_{\mathrm{Tr}}$. (b) Contour plot showing frequency of observations in $C_{\operatorname{Tr}}-\Delta \mathrm{N}_{2} \mathrm{O}$ space. The colours of the contour lines represent number of observations at each combination of $C_{\operatorname{Tr}}$ and $\Delta \mathrm{N}_{2} \mathrm{O}$, and is proportional to the cumulative flux. (c) Histogram of $\Delta \mathrm{N}_{2} \mathrm{O}$ observations (same vertical scale as b). The magenta lines are isoflux lines (i.e. contours of equal flux in units of $\mu \mathrm{g} \mathrm{N} \mathrm{N}_{2} \mathrm{O}-\mathrm{N} \mathrm{m}^{-2} \mathrm{~h}^{-1}$ ) showing particular combinations of $C_{\operatorname{Tr}}$ and $\Delta \mathrm{N}_{2} \mathrm{O}$ that result in the fluxes corresponding to the legend in the top right panel. The horizontal blue line indicates the minimum resolvable $\Delta \mathrm{N}_{2} \mathrm{O}$, referred to in the text as $\Delta \mathrm{N}_{2} \mathrm{O}_{\text {MinRes (equal to }}$ $0.039 \mathrm{ppb})$.

$C_{\operatorname{Tr}}$ and the frequency of concurrent $\mathrm{N}_{2} \mathrm{O}-C_{\operatorname{Tr}}$ observations during the Spring Experiment. The individual populations of $\mathrm{N}_{2} \mathrm{O}$ and $C_{\mathrm{Tr}}$ observations were generally skewed towards smaller values, and combined $\mathrm{N}_{2} \mathrm{O}-C_{\mathrm{Tr}}$ observations were most frequent at $\mathrm{N}_{2} \mathrm{O}$ between 0.05 and $0.10 \mathrm{ppb}$ and $C_{\mathrm{Tr}}$ values between 2.5 and $7.0 \mathrm{~mol}_{\mathrm{Air}} \mathrm{m}^{-2} \mathrm{~s}^{-1}$, which covered the flux range 1.3 to $70.5 \mu \mathrm{g} \mathrm{N}_{2} \mathrm{O}-\mathrm{N} \mathrm{m}^{-2} \mathrm{~h}^{-1}$.

\subsection{Resolution of gradient measurement - expected standard error of $\Delta \mathrm{N}_{2} \mathrm{O}\left(\mathrm{SE}_{\Delta \mathrm{N}_{2} \mathrm{O}-\exp }\right)$ and the minimum resolvable gradient $\left(\Delta \mathrm{N}_{2} \mathrm{O}_{\text {MinRes }}\right)$}

An estimate of the resolution achieved in the field was determined from an assessment of the ensemble $\mathrm{SE}_{\Delta \mathrm{N}_{2} \mathrm{O}}$ for all

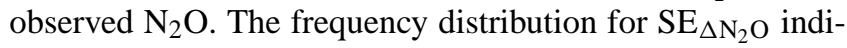
cated that these errors were log-normally distributed (Fig. 7) and that the most likely value was $\mathrm{SE}_{\Delta \mathrm{N}_{2} \mathrm{O}}=0.023 \mathrm{ppb}$. We considered this a conservative estimate of the uncertainty of the FS-NOMAS and refer to this metric as the expected stan-

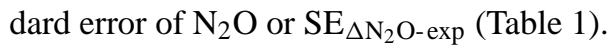

The minimum resolvable value of $\mathrm{N}_{2} \mathrm{O}$ must be significantly different from zero. Using the one-tailed critical Student's $t$ value of 1.648 ( $>450$ degrees of freedom and $P<0.05$ ) (Zar, 1984) we can calculate the minimum resolvable gradient to be

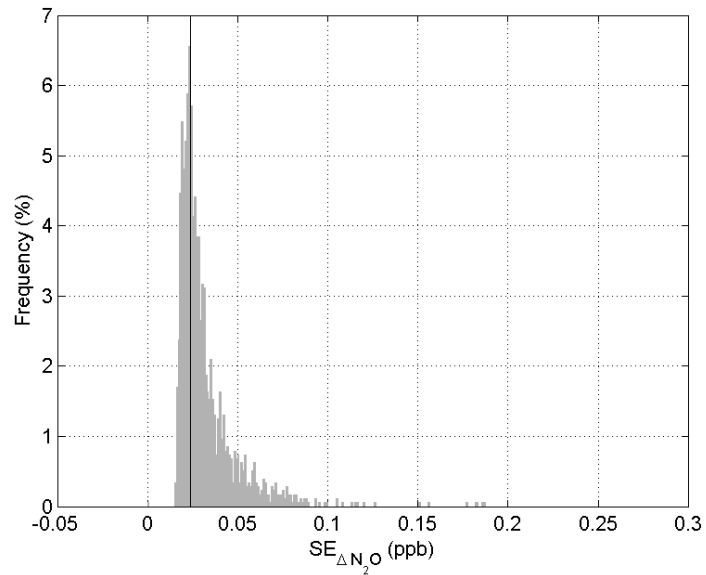

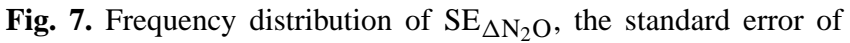
$\Delta \mathrm{N}_{2} \mathrm{O}$. Grey bars indicate the relative frequency for each $0.001 \mathrm{ppb}$

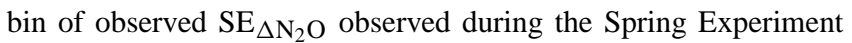
when the $6 \mathrm{~s}$ sampling was used. The vertical line shows the most likely value of $\mathrm{SE}_{\Delta \mathrm{N}_{2} \mathrm{O}}(0.0234 \mathrm{ppb})$.

$t_{\text {crit }} \times \mathrm{SE}_{\Delta \mathrm{N}_{2} \mathrm{O}-\exp }=1.65 \times 0.023 \mathrm{ppb}=0.039 \mathrm{ppb}$. We refer to this metric as $\Delta \mathrm{N}_{2} \mathrm{O}_{\text {MinRes }}$.

The great majority ( $>93 \%$ ) of $\mathrm{N}_{2} \mathrm{O}$ observations were above $\Delta \mathrm{N}_{2} \mathrm{O}_{\text {MinRes }}$, and therefore could be resolved to a confidence level of $95 \%$. The portion of gradients below this value accounted for less than $2 \%$ of the cumulative $\mathrm{N}_{2} \mathrm{O}$ flux. We found that the $6 \mathrm{~s}$ valve switching used in the Spring Ex-

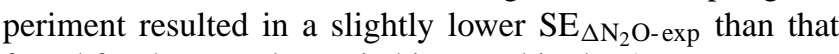
found for the $9 \mathrm{~s}$ valve switching used in the Autumn Experiment (Table 1), so we adopt this valve timing scheme as the recommended option. The reason for the greater precision is not certain but could be either due to a more stable TDLAS signal, or less variance from the optical fringing effects.

The value $\Delta \mathrm{N}_{2} \mathrm{O}_{\text {MinRes }}$ is depicted on Fig. 6 to show that only a small portion of $\mathrm{N}_{2} \mathrm{O}$ observations fell below this value. Of the 182120 min $\mathrm{N}_{2} \mathrm{O}$ determinations observed during this experiment, only $139(7.6 \%)$ observations were below $\Delta \mathrm{N}_{2} \mathrm{O}_{\text {MinRes. }}$. If $\mathrm{N}_{2} \mathrm{O}$ values that were calculated for these small gradients were indeed accurate then they would have accounted for only $\sim 1 \%$ of the total cumulative flux.

The contour lines of constant flux (isoflux lines; Fig. 6b) indicate the range of fluxes that are detectable using the FS-NOMAS. The isoflux line representing $10 \mu \mathrm{g} \mathrm{N}_{2} \mathrm{O}$ $\mathrm{N} \mathrm{m}^{-2} \mathrm{~h}^{-1}$ falls below $\Delta \mathrm{N}_{2} \mathrm{O}_{\text {MinRes }}$ at $C_{\mathrm{Tr}}$ values above 2.6 mol $_{\text {Air }} \mathrm{m}^{-2} \mathrm{~s}^{-1}$, indicating that a flux this small would only be measurable under gentle mixing conditions. The isoflux representing $20 \mu \mathrm{g} \mathrm{N} \mathrm{N}_{2} \mathrm{O}-\mathrm{N} \mathrm{m}^{-2} \mathrm{~h}^{-1}$ falls below $\Delta \mathrm{N}_{2} \mathrm{O}_{\text {MinRes }}$ at $C_{\mathrm{Tr}}$ values of $4.4 \mathrm{~mol}_{\mathrm{Air}} \mathrm{m}^{-2} \mathrm{~s}^{-1}$, close to the median value of $C_{\mathrm{Tr}}$ and suggesting that fluxes of this order can be detected about $50 \%$ of the time. Higher fluxes can be detected under greater ranges of $C_{\mathrm{Tr}}$ : fluxes of $50 \mu \mathrm{g} \mathrm{N} \mathrm{N}_{2} \mathrm{O}$ $\mathrm{N} \mathrm{m}^{-2} \mathrm{~h}^{-1}$ can be detected up to 95 th percentile of $C_{\mathrm{Tr}}$ 

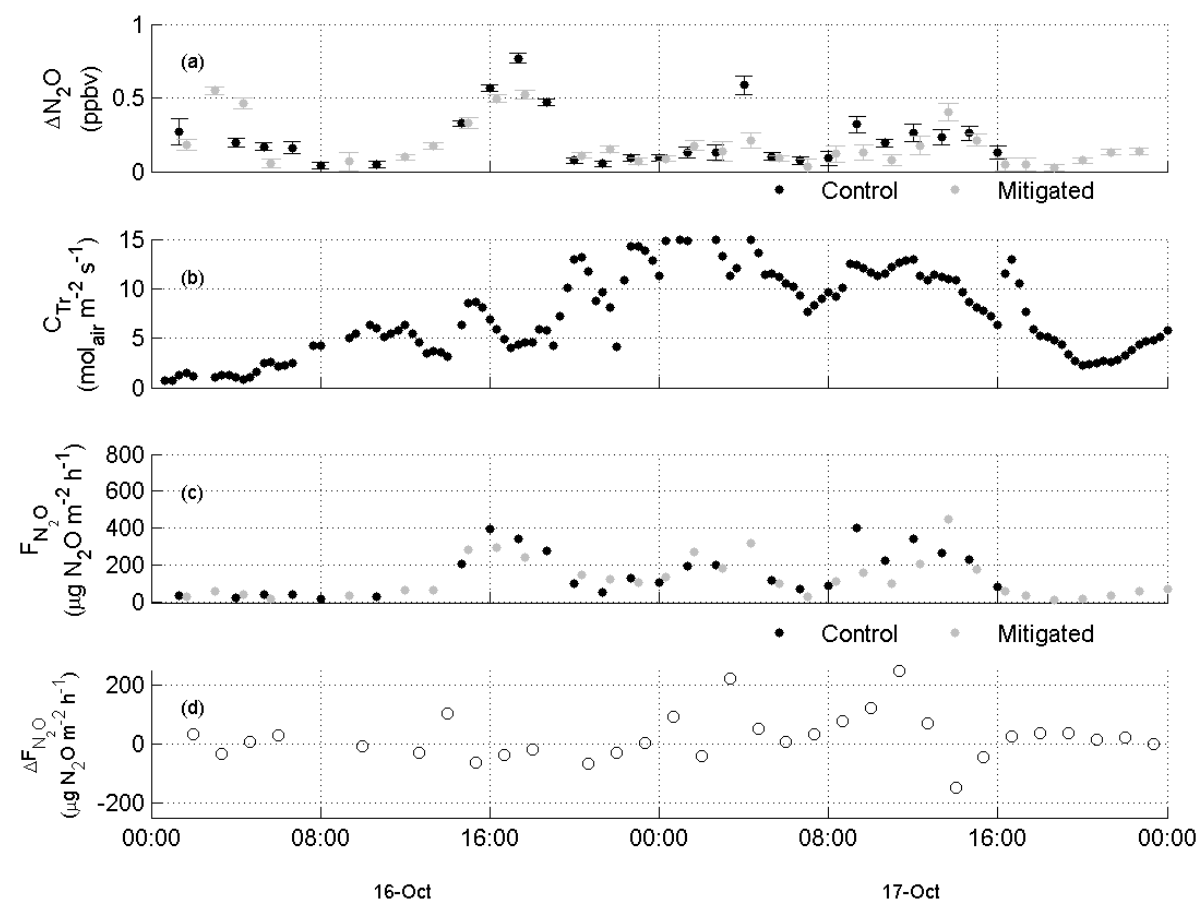

Fig. 8. (a) Time series of $\Delta \mathrm{N}_{2} \mathrm{O}$, (b) transfer coefficient $C_{\mathrm{Tr}}$, (c) $F_{\mathrm{N}_{2} \mathrm{O}}$ and (d) $\Delta F_{\mathrm{N}_{2} \mathrm{O}}$ for a 2-day period (16-17 October 2010). The mitigated treatment was a post-grazing application of $10 \mathrm{~kg} \mathrm{ha}^{-1}$ of a granular formulation of the nitrification inhibitor, dicyandiamide.

values $\left(13 \mathrm{~mol}_{\text {Air }} \mathrm{m}^{-2} \mathrm{~s}^{-1}\right)$, while fluxes of $100 \mu \mathrm{g} \mathrm{N}_{2} \mathrm{O}-$ $\mathrm{N} \mathrm{m}^{-2} \mathrm{~h}^{-1}$ can be detected at any value of $C_{\mathrm{Tr}}$.

\subsection{Time series of $\mathrm{N}_{2} \mathrm{O}$ gradients, transfer coefficients and $\mathrm{N}_{2} \mathrm{O}$ fluxes and flux differences}

Time series of $\Delta \mathrm{N}_{2} \mathrm{O}, C_{\mathrm{Tr}}, F_{\mathrm{N}_{2} \mathrm{O}}$ and $\Delta F_{\mathrm{N}_{2} \mathrm{O}}$ are shown for a $48 \mathrm{~h}$ period in the Spring Experiment to illustrate the determination of $\Delta \mathrm{N}_{2} \mathrm{O}$ in the field, diurnal variation in $C_{\mathrm{Tr}}$ and subsequent calculation of $F_{\mathrm{N}_{2} \mathrm{O}}$ for two treatments and, ultimately, calculation of $\Delta F_{\mathrm{N}_{2} \mathrm{O}}$, the difference in $\mathrm{N}_{2} \mathrm{O}$ emission rates between the two treatments (Fig. 8). Overall, this $24 \mathrm{~h}$ period of data did not indicate obvious differences in $\mathrm{N}_{2} \mathrm{O}$ measured from mitigated versus control plots (Fig. 8a), although there were individual sampling intervals where the differences between $\mathrm{N}_{2} \mathrm{O}$ gradients were clearly resolved. For example, at 10:40 LT on 17 October, $\Delta \mathrm{N}_{2} \mathrm{O}$ values were $0.194 \pm 0.028 \mathrm{ppb}$ and $0.079 \pm 0.036 \mathrm{ppb}$ for the control and mitigated plots, respectively. This translated to a flux of 225 and $97 \mu \mathrm{g} \mathrm{N}_{2} \mathrm{O}-\mathrm{N} \mathrm{m}^{-2} \mathrm{~h}^{-1}$ (for the control and mitigated plots, respectively) and an instantaneous mitigation efficacy of $(225-97) / 225 \times 100 \%=57 \%$. This period was subject to large variations in the transfer coefficient ( $\sim 1$ to $15 \mathrm{~mol}_{\text {Air }} \mathrm{m}^{-2} \mathrm{~s}^{-1}$ ) (Fig. 8b). Despite this variability, the $\mathrm{N}_{2} \mathrm{O}$ differences between consecutive mitigated and control observations translated into broadly corresponding differences of $F_{\mathrm{N}_{2} \mathrm{O}}\left(\Delta F_{\mathrm{N}_{2} \mathrm{O}}\right)$ because hour-to-hour differences in $C_{\mathrm{Tr}}$ were relatively minor.

\section{Discussion}

\subsection{Did we have sufficient measurement precision to detect a mitigation effect?}

The performance metrics of the FS-NOMAS are provided in Table 3. The resolution of the $\mathrm{N}_{2} \mathrm{O}$ in this study was similar to resolutions cited in previous flux gradient studies of $\mathrm{N}_{2} \mathrm{O}$ (Harvey et al., 2008; Pattey et al., 2006; Wagner-Riddle et al., 1996). However, it was not evident from these studies whether the cited resolution was representative of normal operation in the field, or whether it was measured under optimal conditions, so it is difficult to directly compare these metrics. The method of calculating $\Delta \mathrm{N}_{2} \mathrm{O}_{\text {MinRes }}$ here is conservative, as it is based on a $95 \%$ confidence interval rather than the standard error, and uses the peak of the frequency distribution of all standard errors observed as the estimate

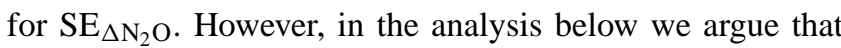
the value of $0.034 \mathrm{ppb}$ that we achieved for $\Delta \mathrm{N}_{2} \mathrm{O}_{\text {MinRes }}$ was sufficiently precise to allow reasonable levels of mitigation efficacy to be detected.

The assessment of mitigation efficacy requires not only that $F_{\mathrm{N}_{2} \mathrm{O}}$ at a particular location can be measured at a high level of precision, but also that inter-plot differences between $F_{\mathrm{N}_{2} \mathrm{O}}\left(\Delta F_{\mathrm{N}_{2} \mathrm{O}}\right)$ can be resolved, e.g. $\Delta F_{\mathrm{N}_{2} \mathrm{O}}$ might be the difference between the $F_{\mathrm{N}_{2} \mathrm{O}}$ of a mitigation treatment $\left(F_{\mathrm{N}_{2} \mathrm{O} \text {-mitigated }}\right)$ and the $F_{\mathrm{N}_{2} \mathrm{O}}$ of a control treatment $\left(F_{\mathrm{N}_{2} \mathrm{O} \text {-control }}\right) . \quad F_{\mathrm{N}_{2} \mathrm{O}}$ measurement ability depends on the 
Table 3. Metrics describing the performance of the FS-NOMAS at measuring $\Delta \mathrm{N}_{2} \mathrm{O}, F_{\mathrm{N}_{2} \mathrm{O}}$ and $\Delta F_{\mathrm{N}_{2} \mathrm{O}}$. The smallest measured gradient was significant at $P<0.05$. $\mathrm{SE}_{\Delta \mathrm{N}_{2} \mathrm{O} \text {-exp }}$ calculated from peak value of all $\mathrm{SE}_{\Delta \mathrm{N}_{2} \mathrm{O}}$ values. $\Delta \mathrm{N}_{2} \mathrm{O}_{\text {MinRes }}$ calculated from one-tailed confidence interval of $\mathrm{SE}_{\Delta \mathrm{N}_{2} \mathrm{O}}$. The associated flux was calculated at the most likely value of the transfer coefficient $C_{\mathrm{Tr}}$, which was $4.8 \mathrm{~mol}_{\mathrm{Air}} \mathrm{m}^{-2} \mathrm{~s}^{-1}$.

\begin{tabular}{llcc}
\hline Metric & Notation & $\begin{array}{c}\text { Value } \\
\mathrm{ppb}\end{array}$ & $\begin{array}{c}\text { Associated flux } \\
\mu \mathrm{g} \mathrm{N} \mathrm{O}_{2}-\mathrm{N} \mathrm{m}^{-2} \mathrm{~h}^{-1}\end{array}$ \\
\hline Smallest measured gradient & & 0.028 & 13.5 \\
Most likely standard error of $\Delta \mathrm{N}_{2} \mathrm{O}$ & $\mathrm{SE}_{\Delta \mathrm{N}_{2} \mathrm{O}-\mathrm{exp}}$ & 0.023 & 11.3 \\
Best estimate of minimum detectable $\Delta \mathrm{N}_{2} \mathrm{O}$ & $\Delta \mathrm{N}_{2} \mathrm{O}_{\text {MinRes }}$ & 0.039 & 18.6 \\
Most frequently observed value of $\Delta \mathrm{N}_{2} \mathrm{O}$ & & 0.055 & 26.7 \\
\hline
\end{tabular}

measurement precision for each of the two variables that multiply to give $F_{\mathrm{N}_{2} \mathrm{O}}, \Delta \mathrm{N}_{2} \mathrm{O}$ and $C_{\text {Tr }}$ (Eq. 4). A carefully designed experimental plot configuration will ensure that plots are subject to similar turbulence regimes so that there are no systematic differences in $C_{\mathrm{Tr}}$ between treatments. Hence, treatment effects on $F_{\mathrm{N}_{2} \mathrm{O}}$ will be detected by measuring inter-plot differences in the $\mathrm{N}_{2} \mathrm{O}$ gradient, $\Delta \mathrm{N}_{2} \mathrm{O}$. Accordingly, we first evaluate the performance of the FSNOMAS in assessing mitigation efficacy by examining how the resolution of the $\mathrm{N}_{2} \mathrm{O}$ measurement affected the resolution of a single instantaneous plot comparison, ignoring the contribution to flux uncertainty from uncertainty in $C_{\mathrm{Tr}}$ (Sect. 4.1.1). We then extend the analysis to incorporate errors in the $C_{\mathrm{Tr}}$ measurement and make a more comprehensive evaluation of performance of the FS-NOMAS in determining differences in cumulative fluxes (Sect. 4.1.2).

\subsubsection{The level of mitigation efficacy that is detectable for a single comparison of plots}

The ability of the FS-NOMAS to detect a mitigation effect can be evaluated by considering the difference between $\mathrm{N}_{2} \mathrm{O}$ gradients measured on consecutive samples, denoted here as $\Delta \Delta \mathrm{N}_{2} \mathrm{O}$ (when the values of $C_{\mathrm{Tr}}$ are similar). We define mitigation efficacy as

$M_{\mathrm{eff}}=\left[F_{\mathrm{N}_{2} \mathrm{O} \text {-control }}-F_{\mathrm{N}_{2} \mathrm{O} \text {-mitigated }}\right] / F_{\mathrm{N}_{2} \mathrm{O} \text {-control }} \times 100 \%$

with the assumption that $C_{\mathrm{Tr}-\mathrm{control}}=C_{\mathrm{Tr} \text {-mitigated }}$. It is apparent that the ability to measure $M_{\text {eff }}$ is entirely dependent on the ability to measure a difference between the two consecutive $\Delta \mathrm{N}_{2} \mathrm{O}$ values, referred to here as $\Delta \Delta \mathrm{N}_{2} \mathrm{O}$.

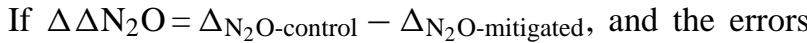
of each are equal, then the uncertainty of $\Delta \Delta \mathrm{N}_{2} \mathrm{O}$ is $\left[2 \mathrm{SE}_{\Delta \mathrm{N}_{2} \mathrm{O}}^{2}\right]^{1 / 2}$. Assuming that our error of each individual $\Delta \mathrm{N}_{2} \mathrm{O}$ measurement $\left(\mathrm{SE}_{\Delta \mathrm{N}_{2} \mathrm{O}}\right)$ is $0.023 \mathrm{ppb}$, then the propagated error of $\mathrm{SE}_{\Delta \mathrm{N}_{2} \mathrm{O}}$ for the difference in gradients, $\mathrm{SE}_{\Delta \Delta \mathrm{N}_{2} \mathrm{O}}=0.033 \mathrm{ppb}$. While this neglects uncertainty in the error in determining the transfer coefficient, $C_{\mathrm{Tr}}$, it quantifies the limits to precision in the $F_{\mathrm{N}_{2} \mathrm{O}}$ measurement originating from the $\Delta \mathrm{N}_{2} \mathrm{O}$ measurement alone.

For the difference in gradients to be statistically significant, $\Delta \Delta \mathrm{N}_{2} \mathrm{O}$ would need to exceed $\mathrm{SE}_{\Delta \Delta \mathrm{N}_{2} \mathrm{O}}$ by a factor of 1.648, which is the critical one-tailed Student's $t$ value at 450 degrees of freedom and $P<0.05$. Therefore, the minimum significant gradient difference that we expect to be able to measure is $\Delta \Delta \mathrm{N}_{2} \mathrm{O}=0.033 \mathrm{ppb} \times 1.648=0.054 \mathrm{ppb}$.

From Eq. (4) and a median value for $C_{\mathrm{Tr}}$ of 4 mol $_{\text {Air }} \mathrm{m}^{-2} \mathrm{~s}^{-1}$ (Fig. 6a) we calculated that the flux difference $F_{\mathrm{N}_{2} \mathrm{O}}$ corresponding to a $\Delta \Delta \mathrm{N}_{2} \mathrm{O}$ of $0.054 \mathrm{ppb}$ would be $26.4 \mu \mathrm{g} \mathrm{N}_{2} \mathrm{O}-\mathrm{N} \mathrm{m}^{-2} \mathrm{~h}^{-1}$. We can compare this value of minimum detectable $F_{\mathrm{N}_{2} \mathrm{O}}$ to typical values of $F_{\mathrm{N}_{2} \mathrm{O}}$ from intensively managed pasture. In intensively farmed dairy pasture in New Zealand, typical values range from 50 to $200 \mu \mathrm{g} \mathrm{N}_{2} \mathrm{O}-\mathrm{N} \mathrm{m}^{-2} \mathrm{~h}^{-1}$ in the several days following grazing when the bulk of $\mathrm{N}_{2} \mathrm{O}$ is emitted (De Klein et al., 2003). If we assume an average flux of $100 \mu \mathrm{g} \mathrm{N} \mathrm{N}_{2} \mathrm{O}-\mathrm{N} \mathrm{m}^{-2} \mathrm{~h}^{-1}$ for around 20 days following grazing, then the ability to detect a $F_{\mathrm{N}_{2} \mathrm{O}}$ of $26.4 \mu \mathrm{g} \mathrm{N}_{2} \mathrm{O}-\mathrm{N} \mathrm{m}^{-2} \mathrm{~h}^{-1}$ indicates that the FSNOMAS is able to detect a mitigation effect of $\sim 26 \%$.

\subsubsection{The level of mitigation efficacy that is detectable for cumulative emissions}

The analysis above examines how the precision of the gradient determination corresponded to the ability to resolve a mitigation effect during a single comparison. In practice, an experimental campaign can extend over several weeks or months so that cumulative emissions can be quantified and emission factors be calculated. Rules of error propagation mean that the relative error of the cumulative flux becomes smaller as the time series of flux measurements becomes longer. The cumulative flux, on average, will be proportional to $n$, the number of individual samplings, while the error on the cumulative flux will be proportional to $\sqrt{n}$. Below we examine how the precision of the gradient measurement affects how well cumulative emissions are measured, using standard rules of error propagation.

We used data collected from a measurement period where differences in cumulative emissions occurred. This period was between 7 October and 30 November in 2010 during the Spring Experiment where the effects of increased nitrogen fertiliser and a granular form of dicyandiamide on $\mathrm{N}_{2} \mathrm{O}$ emission were studied. Grazing and nitrogen addition had occurred on 12 October and a 20 min flux measurement was 
obtained from each plot approximately every $80 \mathrm{~min}$. An error was calculated for each 20 min flux measurement from the square root of the sum of squares (SRSS) of the component errors of the flux calculation:

$\mathrm{SE}_{\mathrm{N}_{2} \mathrm{O}(20 \mathrm{~min})}=F_{\mathrm{N}_{2} \mathrm{O}(20 \mathrm{~min})} \sqrt{\left[\frac{\left[\mathrm{SE}_{\Delta \mathrm{N}_{2} \mathrm{O}}\right]_{20 \mathrm{~min}}}{\Delta \mathrm{N}_{2} \mathrm{O}}\right]^{2}+\left[\frac{\left[\mathrm{SE}_{C_{\mathrm{Tr}}}\right]_{20 \mathrm{~min}}}{C_{\mathrm{Tr}}}\right]^{2}}$,

where $\left[\mathrm{SE}_{\Delta \mathrm{N}_{2} \mathrm{O}}\right]_{20 \mathrm{~min}} / \Delta \mathrm{N}_{2} \mathrm{O}$ was the individual relative error for each $\mathrm{N}_{2} \mathrm{O}$ gradient and $\left[\mathrm{SE}_{C_{\mathrm{Tr}}}\right]_{20 \mathrm{~min}} / C_{\mathrm{Tr}}$ was the average relative error term for the transfer coefficient $C_{\mathrm{Tr}}$, which was found to be 0.12 from a detailed Monte Carlo-based error analysis for this term (Mukherjee et al., 2013).

We aggregated the data to $4 \mathrm{~h}$ intervals so that we had valid observations for at least one control plot and each treatment plot. The fluxes were log-normally distributed so geometric means were used as the measure of central tendency within each interval. Errors in the fluxes for the $4 \mathrm{~h}$ interval were calculated from the SRSS of the individual 20 min $\mathrm{SE}_{F_{\mathrm{N}_{2} \mathrm{O}}}$ values. Errors within each 4-hourly flux were large relative to the magnitude of the fluxes, indicating that evaluating mitigation efficacy during short intervals is difficult (Fig. 9a).

The cumulative fluxes and associated errors provide a clearer indication of the ability of the FS-NOMAS to detect an effect of the field treatments (Fig. 9b). Cumulative fluxes were from the 4-hourly fluxes (to ensure equal numbers of observations from each plot). Cumulative errors were calculated at each time step from the SRSS of the current and all previous errors.

For the purpose of this analysis, which is to compare the magnitude of cumulative flux with cumulative flux error, we ignored the contribution to uncertainty from periods when no measurements were available ( $36 \%$ of the time in this case). We assume that errors from such periods were representative of sampled periods and that their magnitude relative to that of the cumulative flux would also be similar to that of sampled periods. However, we note that the absolute value of the cumulative flux over this period would need to be adjusted to account for data gaps.

Having acknowledged that this analysis is restricted only to the 110 4-hourly intervals when at least one flux from each type of treatment plot was observed, we can now compare the magnitude of the cumulative fluxes with their corresponding errors. The cumulative sum of $\mathrm{N}_{2} \mathrm{O}$ fluxes were $401 \pm 26 \mathrm{~g} \mathrm{~N}_{2} \mathrm{O}-\mathrm{N} \mathrm{ha}^{-1}$ from the control plot, $368 \pm 16 \mathrm{~g} \mathrm{~N}_{2} \mathrm{O}-\mathrm{N} \mathrm{ha}^{-1}$ from the mitigant-treated plot and $468 \pm 20 \mathrm{~g} \mathrm{~N}_{2} \mathrm{O}-\mathrm{N} \mathrm{ha}^{-1}$ from the double-N plot (Fig. 9b).

Compared to the control plot, the cumulative emissions from the mitigant-treated plot were $8.3 \%$ smaller, but this difference was not significant at the $95 \%$ level of confidence. However, the cumulative analysis does show consistently larger emission from the control plot over a period of 1 week at the end of the period presented. In contrast, the cumulative emissions from the double-N plot were $18.4 \%$ higher and this difference was significant (at the $95 \%$ level of confidence).
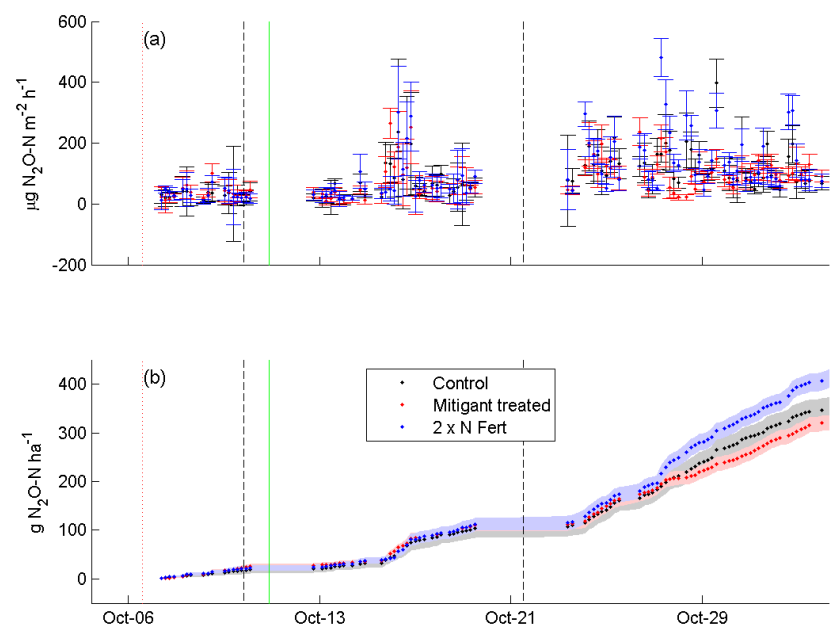

Fig. 9. $\mathrm{N}_{2} \mathrm{O}$ fluxes averaged over $4 \mathrm{~h}$ intervals (a) and cumulative $\mathrm{N}_{2} \mathrm{O}$ fluxes over corresponding interval with error bounds indicated by shaded regions (b). The dashed vertical lines indicate the timing of grazing (black), double or single (control) $\mathrm{N}$ fertilisation (green) and dicyandiamide application (red). Note the use of different $y$ axis units between the upper and lower panels.

Given that the cumulative fluxes from the control plot were $401 \mathrm{~g} \mathrm{~N}_{2} \mathrm{O}-\mathrm{N} \mathrm{ha}^{-1}$, we can also calculate the minimum measurable detectability of field treatment effects. The relative error for the control plot is $6.5 \%$, higher than that for the treatment plots. If we assume that this is a typical error, than the standard error of the difference between two fluxes with errors of this magnitude would be $\mathrm{SE}_{\Delta \mathrm{N}_{2} \mathrm{O}}=\left[2 \times 26^{2}\right]^{1 / 2}=36.6 \mathrm{~g} \mathrm{~N}_{2} \mathrm{O}-\mathrm{N} \mathrm{ha}^{-1}$. For a flux difference $\Delta F_{\mathrm{N}_{2} \mathrm{O}}$ to be statistically significant, it must be a factor of $t_{\text {crit }}$ greater than $\mathrm{SE}_{\Delta \mathrm{N}_{2} \mathrm{O}}$. Here, $t_{\text {crit }}$ is $1.97(P>0.05$, degrees of freedom $=218$ ). Therefore the minimum measurable flux difference is $t_{\text {crit }} \times \mathrm{SE}_{\Delta \mathrm{N}_{2} \mathrm{O}}=72.2 \mathrm{~g} \mathrm{~N}_{2} \mathrm{O}-\mathrm{N} \mathrm{ha}^{-1}$. This is $18 \%$ of the control plot flux. This minimum measurable difference was persistently exceeded by the differences between the double- $\mathrm{N}$ treatment and the control treatment from 23 days after the $\mathrm{N}$ application onwards. However, in the same time period, the minimum measurable difference was not exceeded by the differences between the mitiganttreated treatment plot and the control treatment.

We recognise that propagating error along time series is potentially problematic due to a lack of independence between consecutive samples. An alternative approach to estimating the cumulative error would entail a comprehensive modelling of the sources of variability (including serial correlation). Such an approach would introduce new uncertainties because it would involve choosing and parameterising a model, and interpolation of the incomplete time series. The main uncertainty in the approach undertaken here - that cumulative error might be underestimated due to autocorrelation of the data - has the possible effect that small but 
persistent field treatment effects would take longer to become detectable.

In both approaches to assessing the resolution of the technique, the quantification of diffusivity involves uncertainty. This uncertainty is due to possible error in the assumptions of equal diffusivities in heat, momentum and gas under neutral conditions and how the differences in these terms is parameterised under non-neutral conditions. Fortunately, the errors are unlikely to vary systematically with the effectiveness of a mitigation strategy, which will be focused on reducing the rate of $\mathrm{N}_{2} \mathrm{O}$ production in the soil, and would therefore affect the $\Delta \mathrm{N}_{2} \mathrm{O}$ term rather than the $C_{\mathrm{Tr}}$ term of Eq. (4).

\subsection{How would the technique perform in a field-scale version of a previously reported $\mathrm{N}_{2} \mathrm{O}$ mitigation study?}

Having assessed the ability of the FS-NOMAS to detect differences between plots in a study where the field treatment effect was small, we now assess its hypothetical performance in a previously reported experiment where the mitigation effect was comparatively large. We refer to the study by $\mathrm{Di}$ and Cameron (2006), but scaled to the field. In their study, $\mathrm{N}_{2} \mathrm{O}$ emissions were measured from intact soil columns contained in lysimeters. The soil type used in this study was similar to that of the current study (Lismore Silt Loam) and $\mathrm{N}_{2} \mathrm{O}$ emissions were measured by static chambers following amendment with cattle urine, urea and, in one treatment, an application of $10 \mathrm{~kg} \mathrm{ha}^{-1}$ of DCD. This study aimed to quantify the emissions from a recent urine patch and concluded that DCD application at this rate and on this soil type resulted in a $M_{\text {eff }}$ of $70 \%$.

The absolute $\mathrm{N}_{2} \mathrm{O}$ emissions from the Di and Cameron (2006) study have been digitised from the original paper and scaled to a whole field, assuming that urine patches cover $2 \%$ of the surface (Moir et al., 2011) and the remaining $98 \%$ of the surface emits $10 \mu \mathrm{g} \mathrm{N} \mathrm{O}_{2} \mathrm{O}-\mathrm{N} \mathrm{m}^{-2} \mathrm{~h}^{-1}$. It is assumed here that DCD would be equally effective on the emissions from urine patches and the other $98 \%$ of the field (non-urine patch area). Over the entire period of measurements, the background emissions accounted for $32 \%$ (control treatment) and $43 \%$ (DCD treatment) of cumulative emissions. The time series of field-scale $\mathrm{N}_{2} \mathrm{O}$ fluxes that the FS-NOMAS would be required to measure is given in Fig. 10a. The difference in these fluxes $\left(\Delta F_{\mathrm{N}_{2} \mathrm{O}}\right)$ between the treated and untreated plots is shown in Fig. 10b.

As discussed earlier, the smallest detectable flux difference for the FS-NOMAS depends on the extent of atmospheric mixing. The minimum resolvable gradient $\left(\Delta \mathrm{N}_{2} \mathrm{O}_{\text {MinRes }}\right)$ is associated with higher fluxes under well-mixed conditions (high $C_{\mathrm{Tr}}$ ) than under stable conditions (low $C_{\mathrm{Tr}}$ ). The horizontal lines in Fig. 10b indicated the ability of the FS-NOMAS to resolve $\mathrm{N}_{2} \mathrm{O}$ fluxes at three different values of $C_{\text {Tr }}$, which are the 50th, 75th and 95th percentile of $C_{\mathrm{Tr}}$. At the very largest values of $C_{\mathrm{Tr}}$, only the
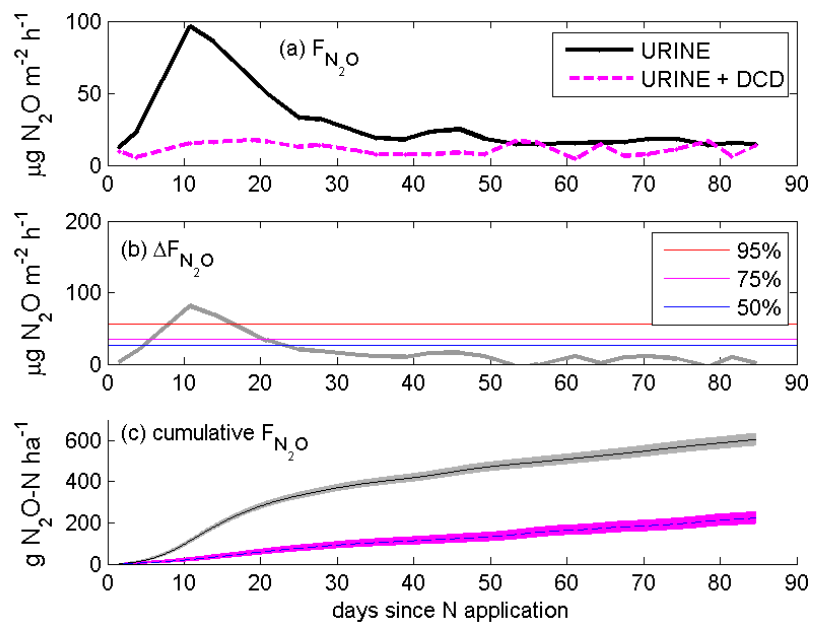

Fig. 10. Field-scale $F_{\mathrm{N}_{2} \mathrm{O}}, \Delta F_{\mathrm{N}_{2} \mathrm{O}}$ and cumulative $F_{\mathrm{N}_{2} \mathrm{O}}$ based on $\mathrm{N}_{2} \mathrm{O}$ fluxes measured from lysimeters receiving controlled $\mathrm{N}$ (control) and controlled $\mathrm{N}$ plus the nitrification inhibitor dicyandiamide (mitigated). Data have been digitised from Fig. 2a in Di and Cameron (2006). (a) Time series of fluxes measured by static chambers and scaled to a whole field; (b) time series of difference in flux $\left(\Delta F_{\mathrm{N}_{2} \mathrm{O}}\right.$ ). Horizontal lines represent the ability of the FS-NOMAS to detect the mitigation effect in a single instantaneous comparison of plots at different values of the transfer coefficient $C_{\mathrm{Tr}}$, representing the 50th, 75th and 95th percentile of all $C_{\mathrm{Tr}}$ measured during the Spring Experiment; (c) cumulative fluxes from the control and mitigated plots. The digitised time series of fluxes have been interpolated to a $4 \mathrm{~h}$ time step and errors have been estimated by bootstrapping errors from field measurements and propagated in time as in Fig. 9.

largest differences between the treatments were measurable. At the 95th percentile where $C_{\mathrm{Tr}}=10.2 \mathrm{~mol}_{\mathrm{Air}} \mathrm{m}^{-2} \mathrm{~s}^{-1}$, the FS-NOMAS could only detect differences in excess of $56.2 \mu \mathrm{g} \mathrm{N} \mathrm{N}_{2} \mathrm{O}-\mathrm{N} \mathrm{m}^{-2} \mathrm{~h}^{-1}$. At the 75th percentile where $C_{\mathrm{Tr}}=6.3 \mathrm{~mol}_{\mathrm{Air}} \mathrm{m}^{-2} \mathrm{~s}^{-1}$, only differences in excess of $34.4 \mu \mathrm{g} \mathrm{N} \mathrm{N}_{2} \mathrm{O}-\mathrm{N} \mathrm{m}^{-2} \mathrm{~h}^{-1}$ could be detected. The median (50th percentile) value of $C_{\operatorname{Tr}}$ was $4.8 \mathrm{~mol}_{\text {Air }} \mathrm{m}^{-2} \mathrm{~s}^{-1}$ which means that differences above $26.4 \mu \mathrm{g} \mathrm{N} \mathrm{N}_{2} \mathrm{O}-\mathrm{N} \mathrm{m}^{-2} \mathrm{~h}^{-1}$ could be detected.

Finally we generate a new data set, based on the chamber flux data of Di and Cameron (2006), but with measurement error characteristics and a sampling rate similar to that of the FS-NOMAS. The Di and Cameron (2006) data were interpolated to a $4 \mathrm{~h}$ sampling interval and standard errors for each interval were calculated by repeated random sampling of the propagated errors of the 4-hourly fluxes collected during the trials of the FS-NOMAS described in Sect. 4.1.2. The time series of the random errors were propagated through time in the same way as described in Sect. 4.1.2 so that the cumulative error can be compared to the magnitude of the cumulative fluxes. The results of this analysis indicated that the effect of the mitigation treatment observed in the Di and Cameron (2006) experiment would 
have been clearly resolved by the FS-NOMAS. Cumulative fluxes were $604 \pm 28 \mathrm{~g} \mathrm{~N}_{2} \mathrm{O}-\mathrm{N} \mathrm{ha}^{-1}$ from the control plot and $224 \pm 12 \mathrm{~g} \mathrm{~N}_{2} \mathrm{O}-\mathrm{Nha}^{-1}$ from the mitigated plot. According to this method of error propagation, significant differences between the treatments would have been detectable with the FS-NOMAS within the first week of measurements.

\subsection{Flux footprint as a source of uncertainty}

The reliability of field-scale (micrometeorological) approaches for mitigation assessment is also dependent on the extent to which the measured gradients were affected by fluxes from outside the area of interest, namely the $100 \mathrm{~m} \times 155 \mathrm{~m}$ plot immediately upwind of the sampled inlets. In designing the experimental layout we used the heuristic rule that $100 \mathrm{~m}$ of upwind fetch was required per $1 \mathrm{~m}$ of measurement height (Monteith and Unsworth, 1990). However, under stable conditions the source area can be considerably longer and gradients measured at a particular mast may be contaminated with fluxes originating from the areas outside of the plot immediately adjacent to the mast. We used a spreadsheet implementation (Neftel et al., 2008) of a well-established analytical footprint model (Kormann and Meixner, 2001) to assess the importance of this issue. This analysis indicated that gradients measured at the masts were predominantly affected by fluxes that originated from within the immediately upwind plot, and only $4.3 \%$ of the cumulative flux originated from fluxes occurring outside of this area (Mukherjee, 2013).

\subsection{Reconciling measurements at different scales}

The high rate of $\mathrm{N}_{2} \mathrm{O}$ flux from excreta patches is responsible for the patchy nature of $\mathrm{N}_{2} \mathrm{O}$ emissions. Because the spatial scale of this variability is similar to that of a static flux chamber, it is difficult to obtain representative sampling when randomly placing replicate chambers within different treatment plots. For this reason, the majority of chamber sampling experiments to determine mitigation efficacy in New Zealand grazing systems are made on replicated experimental plots where inputs of nitrogen are controlled to simulate natural urine or dung events (Gillingham et al., 2012). Both the excreta-treated and untreated plots are then subjected to the mitigation treatment. Results from studies that use this experimental design have been used to support New Zealand's successful application to the United Nations Framework Convention on Climate Change (NZFCCC) to claim emissions reduction for the use of nitrification inhibitors within its national greenhouse gas inventory (Clough et al., 2007). However, the upscaling of emissions measured at this scale to an estimate at the field scale is complicated because of uncertainties regarding the quantity and evenness of excreta- $\mathrm{N}$ distribution and differences between the implementation of the mitigation at the experimental scale versus the managementrelevant field scale.
Understanding these scaling issues is critical to reconciling measurements made with chambers with measurements made using micrometeorological approaches. Upscaling from chamber measurements requires reliable estimates of the excreta-N deposition following a grazing event. Recent research has begun to address the spatial distribution of urine events in grazed pasture (Betteridge et al., 2010; MacKenzie et al., 2011; Moir et al., 2011). Combining knowledge of the spatial distribution of excreta- $\mathrm{N}$ deposition with characteristic urine and non-urine patch fluxes from mitigated and nonmitigated treatments will be required to perform a satisfactory reconciliation of measurements at these scales.

\subsection{Potential technical improvements}

The FS-NOMAS has proven reliability over several months (this work) and in longer-term studies (Pattey et al., 2006; Wagner-Riddle et al., 1996), and therefore application to determining annual fluxes and efficacy of mitigation practices over these longer time scales. The logistics of longer-term deployments in the current configuration are challenging as the field measurements need to be suspended while the field is being grazed. The main reason for removal is to avoid animal-inflicted damage to the instrumentation. However, for deployments which exceed several months, signal and power cables extending from the instruments to the sampling masts could be buried and instrumentation and air tubes could be protected by electric fencing. A system of this complexity would require at least a once-weekly visit to perform site maintenance and a liquid nitrogen top-up for the TDLAS.

In the current version of the FS-NOMAS, gradients from different masts could not be measured concurrently because the TDLAS measurement sub-system was directly coupled to the sample collection sub-system (the gradient valve assemblies) via the mast selection manifold (Fig. 2). This meant that the gradient at an individual mast could be measured 12 times a day in the Autumn Experiment and 18 times a day in the Spring Experiment. Further, the gradients measured sequentially within the four-mast measurement cycle were associated with different values of $C_{\mathrm{Tr}}$.

An improvement upon the current system could be made by decoupling the sample collection from the sample measurement by simultaneously collecting air from $z_{1}$ and $z_{2}$ at all the masts and temporarily storing the samples in Tedlar Bags close to the TDLAS over a 20-30 min interval. Meanwhile the TDLAS analyses a separate set of identical bags that were collected in the previous interval. The measurement system could then make rapid comparisons between each of the bags, determining $F_{\mathrm{N}_{2} \mathrm{O}}$. The analysis sub-system would retrieve the stored samples and present them to the TDLAS in a manner that is optimal for that instrument. A forerunner for such a system has been developed (Martin et al., 2011) and used for long-term gas chromatograph-based measurement. 


\section{Conclusions}

This paper has described the development and deployment of a sample collection and measurement system to measure nitrous oxide fluxes suitable for assessing mitigation efficacy at the field scale. It comprised a micrometeorological system with a single TDLAS analyser capable of high-resolution measurements of $\mathrm{N}_{2} \mathrm{O}$ gradients at four separate locations along a $300 \mathrm{~m}$ transect. This allowed comparison of nitrous oxide flux between mitigation treatment plots and control plots. The resolution of the gradient measurement was sufficient to resolve a flux difference between plots of $26 \mu \mathrm{g} \mathrm{N} \mathrm{N}_{2} \mathrm{O}$ $\mathrm{N} \mathrm{m}^{-2} \mathrm{~h}^{-1}\left(6 \mathrm{~g} \mathrm{~N}_{2} \mathrm{O}-\mathrm{N} \mathrm{ha}^{-1} \mathrm{~d}^{-1}\right)$ for an instantaneous comparison. This corresponds to the ability to detect a mitigation effect of $26 \%$ under typical post-grazing $\mathrm{N}_{2} \mathrm{O}$ fluxes of $100 \mu \mathrm{g} \mathrm{N} \mathrm{N}_{2} \mathrm{O}-\mathrm{N} \mathrm{m}^{-2} \mathrm{~h}^{-1}$. Small differences (18\%) in cumulative $\mathrm{N}_{2} \mathrm{O}$ flux resulting from differences in nitrogen fertiliser treatments were detectable after 23 days. If the measurement system had been deployed in a field-scale version of a previously published chamber plot experiment study that showed a $70 \%$ mitigation efficacy, treatment differences would have been detectable after 4 days of measurement.

Acknowledgements. This experimental work was funded by the Sustainable Land Management and Adaptation to Climate Change Fund of the Ministry for Agriculture and Forestry (now Ministry for Primary Industries) contract CO1X0816, by New Zealand's Foundation of Research, Science and Technology (FRST) until 2011. Subsequent analysis has been funded by Landcare Research and by NIWA's Atmosphere Research Programme 3 (2011/13 SCI). We are grateful to the MacKenzie family for the permission to use their land and for their kind logistical support. Jens Dalhaussen, Joanna Hasselbach and Mark Cooper provided invaluable field assistance. Frank Kelliher (AgResearch), Keith Cameron, Hong Di, Tim Clough and Rob Sherlock at Lincoln University provided valuable feedback to an earlier draft of this paper, which has stimulated useful discussion and careful reanalysis of the results. Keith Lassey also provided useful criticism and many helpful comments at earlier stages. We also thank Gordon Brailsford (NIWA) for a wealth of advice during the development of this measurement system.

Edited by: D. Griffith

\section{References}

Allan, D. W.: Statistics of atomic frequency standards, Proc. IEEE, 54, 221-230, 1966

Betteridge, K., Hoogendoorn, C., Costall, D., Carter, M., and Griffiths, W.: Sensors for detecting and logging spatial distribution of urine patches of grazing female sheep and cattle, Comput. Electron. Agr., 73, 66-73, 2010.
Clough, T. J., Di, H. J., Cameron, K. C., Sherlock, R. R., Metherell, A. K., Clark, H., and Rys, G.: Accounting for the utilization of a $\mathrm{N}_{2} \mathrm{O}$ mitigation tool in the IPCC inventory methodology for agricultural soils, Nutr. Cycl. Agroecosys., 78, 1-14, 2007.

De Klein, C. A. M., Barton, L., Sherlock, R. R., Li, Z., and Littlejohn, R. P.: Estimating an emission factor for animal urine from some New Zealand soils, Aust. J. Soil Res., 41, 381-399, 2003.

Denmead, O. T., Simpson, J. R., and Freney, J. R.: Ammonia Flux into the atmosphere from a grazed pasture, Science, 185, 609610,1974

Di, H. J. and Cameron, K. C.: Nitrous oxide emissions from two dairy pasture soils as affected by different rates of a fine particle suspension nitrification inhibitor, dicyandiamide, Biol. Fert. Soils, 42, 472-480, 2006.

Edwards, G. C., Neumann, H. H., Denhartog, G., Thurtell, G. W. and Kidd, G.: Eddy-correlation measurements of methane fluxes using a tunable diode-laser at the Kinosheo Lake tower site during the Northern Wetlands Study (Nowes), J. Geophys. Res.Atmos., 99, 1511-1517, 1994.

Flesch, T. K., Prueger, J. H., and Hatfield, J. L.: Turbulent Schmidt number from a tracer experiment, Agr. Forest Meteorol., 111, 299-307, 2002.

Foken, T.: Micrometeorology, Springer-Verlag, Berlin, 2006.

Gillingham, A. G., Ledgard, S. F., Saggar, S., Cameron, K. C. Di, H. J., de Klein, C. A. M., and Aspin, M.: Initial evaluation of the effects of dicyandiamide (DCD) on nitrous oxide emissions, nitrate leaching and dry matter production from dairy pastures in a range of locations within New Zealand, Tech. rep., Massey University, Palmerston North, New Zealand, 2012.

Giltrap, D. L., Saggar, S., Singh, J., Harvey, M. J., McMillan, A. M. S., and Laubach, J.: Field-scale verification of nitrous oxide emission reduction with DCD in dairy-grazed pasture using measurements and modelling, Soil Res., 49, 696-702, 2012.

Harvey, M. J., Pattey, E., Saggar, S., Bromley, T., Dow, D., Kotkamp, M., Martin, R., Moss, R., and Singh, J.: Verification techniques for $\mathrm{N}_{2} \mathrm{O}$ emission at the paddock scale in New Zealand: FarmGas2006, Aust. J. Exp. Agr., 48, 138-141, 2008.

Hendriks, D. M. D., Dolman, A. J., van der Molen, M. K., and van Huissteden, J.: A compact and stable eddy covariance set-up for methane measurements using off-axis integrated cavity output spectroscopy, Atmos. Chem. Phys., 8, 431-443, doi:10.5194/acp-8-431-2008, 2008.

Hewitt, A. E.: New Zealand Soil Classification, Landcare Research Manaaki Whenua, Lincoln, New Zealand, 1988.

Högström, U.: Non-dimensional wind and temperature profiles in the atmospheric surface layer: a re-evaluation, Bound.-Lay. Meteorol., 42, 55-78, 1988.

Huber, B.: Der Elnfluss der Vegetation auf die Schwankungen des $\mathrm{CO}_{2}$-Gehlates der Atmosphäre, Arch. Meteorol. Geophys. Blokllma., 84, doi:10.1007/BF02243633, 1952.

IPCC: Climate Change 2007: The Physical Science Basis, Contribution of Working Group I to the Fourth Assessment Report of the Intergovernmental Panel on Climate Change, Tech. rep., Cambridge University Press, 2007.

Kormann, R. and Meixner, F. X.: An analytical footprint model for non-neutral stratification, Bound.-Lay. Meteorol., 99, 207-224, 2001. 
Laville, P., Jambert, C., Cellier, P., and Delmas, R.: Nitrous oxide fluxes from a fertilised maize crop using micrometeorological and chamber methods, Agr. Forest Meteorol., 96, 19-38, 1999.

MacKenzie, J., Christianson, R., MacKenzie, C., and Yule, I. J.: Adaptation of optical sensors to detect urine and dung patches in dairy pasture, Tech. rep., Fertilizer and Lime Research Center, Massey University, Palmerston North, New Zealand, 2011.

Maggiotto, S. R., Webb, J. A., Wagner-Riddle, C., and Thurtell, G. W.: Nitrous and nitrogen oxide emissions from turfgrass receiving different forms of nitrogen fertilizer, J. Environ. Qual., 29, 621-630, 2000.

Mammarella, I., Werle, P., Pihlatie, M., Eugster, W., Haapanala, S., Kiese, R., Markkanen, T., Rannik, Ü., and Vesala, T.: A case study of eddy covariance flux of $\mathrm{N}_{2} \mathrm{O}$ measured within forest ecosystems: quality control and flux error analysis, Biogeosciences, 7, 427-440, doi:10.5194/bg-7-427-2010, 2010.

Martin, R. J., Bromley, A. M., Harvey, M. J., Moss, R. C., Pattey, E., and Dow, D.: The "Lung": a software-controlled air accumulator for quasi-continuous multi-point measurement of agricultural greenhouse gases, Atmos. Meas. Tech., 4, 2293-2303, doi:10.5194/amt-4-2293-2011, 2011.

Ministry for the Environment: New Zealand greenhouse gas inventory 1990-2011, Tech. rep., Ministry for the Environment, Wellington, New Zealand, 2013.

Miyata, A., Leuning, R., Denmead, O. T., Kim, J., and Harazono, Y.: Carbon dioxide and methane fluxes from an intermittently flooded paddy field, Agr. Forest Meteorol., 102, 287-303, 2000.

Moir, J. L., Cameron, K. C., Di, H. J., and Fertsak, U.: The spatial coverage of dairy cattle urine patches in an intensively grazed pasture system, J. Agr. Sci., 149, 473-485, 2011.

Monteith, J. L. and Szeisz, K. C.: The carbon-dioxide flux over a field of sugar beet, Q. J. Roy. Meteorol. Soc., 86, 205-214, 1960.

Monteith, J. L. and Unsworth, M. H.: Principles of Environmental Physics, 2nd Edn., Edward Arnold, London, 1990.

Mukherjee, S.: On the estimation of nitrous oxide flux from agricultural fields of New Zealand using micrometeorological techniques, Ph. D. thesis, University of Canterbury, 2013.
Mukherjee, S., Sturman, A. P., McMillan, A. M. S., Harvey, M. J., and Zawar-Reza, P.: Assessment of error propagation in measured flux values obtained using an eddy diffusivity based micrometeorological setup, Atmos. Environ., 84, 144-155, doi:10.1016/j.atmosenv.2013.10.034, 2013.

Neftel, A., Spirig, C., and Ammann, C.: Application and test of a simple tool for operational footprint evaluations, Environ. Pollut., 152, 644-652, 2008.

Pattey, E., Edwards, G., Strachan, I. B., Desjardins, R. L., Kaharabata, S., and Wagner-Riddle, C.: Towards standards for measuring greenhouse gas fluxes from agricultural fields using instrumented towers, Can. J. Soil Sci., 86, 373-400, 2006.

Paulson, C. A.: The mathematical representation of wind speed and temperature profiles in the unstable surface layer, J. Clim. Appl. Meteorol., 9, 857-861, 1970.

Phillips, F. A., Leuning, R., Baigenta, R., Kelly, K. B., and Denmead, O. T.: Nitrous oxide flux measurements from an intensively managed irrigated pasture using micrometeorological techniques, Agr. Forest Meteorol., 143, 92-105, 2007.

Wagner-Riddle, C. and Thurtell, G. W.: Nitrous oxide emissions from agricultural fields during winter and spring thaw as affected by management practices, Nutr. Cycl. Agroecosys., 52, 151-163, 1998.

Wagner-Riddle, C., Thurtell, G. W., Kidd, G. E., Edwards, G. C., and Simpson, I. J.: Micrometeorological measurements of trace gas fluxes from agricultural and natural ecosystems, Infrared Phys. Techn., 37, 51-58, 1996.

Wagner-Riddle, C., Furon, A., Mclaughlin, N. L., Lee, I., Barbeau, J., Jayasundara, S., Parkin, G., von Bertoldi, P., and Warland, J.: Intensive measurement of nitrous oxide emissions from a corn-soybean-wheat rotation under two contrasting management systems over 5 years, Global Change Biol., 13, 1722-1736, 2007.

Zar, J. H.: Biostatistical Analysis, 2nd Edn., Prentice Hall, Inc, Englewood Cliffs, New Jersey, 1984. 